\title{
MOVILIDAD SOCIAL Y CAMBIO SOCIAL EN ESPAÑA*
}

\author{
Jorge Rodríguez Menés
}

Northwestern University, Evanston, Illinois (EE.UU.)

\section{INTRODUCCION}

A diferencia de otros países europeos y de los Estados Unidos, donde los estudios sobre «movilidad social» constituyen un punto de referencia obligado para el estudio de la desigualdad social ${ }^{1}$, en España sólo unos pocos investigadores se han interesado por este tema ${ }^{2}$. Los pocos estudios empíricos

* Este artículo fue presentado como tesis de Master en el Departamento de Sociología de la Universidad norteamericana de Northwestern, dentro de su programa de Doctorado. Agradezco el apoyo prestado por todos los miembros del Departamento, en especial al director de mi comité, Arnold S. Feldman, por su paciencia y consejos, sin cuya dedicación este trabajo no habría visto la luz. Agradezco también los valiosos comentarios al primer borrador de este trabajo por parte de los otros dos miembros del comité, Arthur L. Stinchcombe y Christopher Winship, y a Charles Ragin y a los miembros del seminario sobre «La lógica del análisis», por él impartido, por prestarse amablemente a criticar los primeros pasos de la investigación. Agradezco al Centro de Investigaciones Sociológicas el que pusiera a mi disposición los datos en los que se basa este trabajo. Por último, agradezco a Julio Carabaña su apoyo desinteresado y sus certeros comentarios, y el que me permitiera utilizar su versión de la escala de prestigio de Treiman, en la que se basa en gran parte esta investigación.

I Una detallada y rigurosa revisión crítica de la literatura española y extranjera sobre movilidad social está a disposición de los lectores españoles en Lorenzo Cachón (1989). Para lectores en inglés, la colección de artículos en Ronald L. Breiger (1990) ofrece una interesante revisión de los últimos avances y perspectivas en el estudio de la movilidad.

2 Tal y como se recoge en el ya mencionado trabajo de Lorenzo Cachón (1989: 11), esos estudios se centraron fundamentalmente en el análisis de las élites y las motivaciones. 
sobre movilidad social en España datan de los años sesenta y principios de los setenta ${ }^{3}$, una época en la que las condiciones políticas del país hacían muy difícil el poder contar con datos fiables. Esta relativa ausencia de interés por el estudio de la movilidad social en España no debe achacarse, a mi entender, a una falta de relevancia teórica de este tema respecto a nuestro país, pues los cambios «estructurales» experimentados en España en las últimas décadas convierten a este país en un caso único para el estudio de algunas de las teorías e hipótesis más interesantes dentro de la literatura sobre la «movilidad social», concretamente aquellas que la relacionan con el «cambio social».

El propósito de este artículo es el de empezar a rellenar esta laguna. Intentaré poner los cimientos para la realización de un análisis riguroso sobre las pautas y tendencias de la movilidad social en España en los últimos cincuenta años, enfatizando su conexión con los cambios estructurales experimentados por el país. La disponibilidad de nuevos datos fiables hace posible acometer esta empresa por primera vez, aunque la hace más difícil, en la medida en que casi todo está aún por hacer. Esta investigación debe considerarse como un primer paso en la realización de un análisis comprensivo sobre la estructura social en España, en el que otros investigadores y yo mismo estamos actualmente inmersos.

En muchos aspectos, esta investigación pertenece a la tradición del «logro de estatus» (status attainment), que intenta establecer y explicar la relación entre las posiciones ocupacionales alcanzadas por los individuos y sus orígenes sociales e historiales educacionales. En la investigación intento determinar también los efectos que los cambios económicos, políticos y sociales han ejercido sobre las oportunidades de movilidad intergeneracional en España. Estimo que esas oportunidades aumentaron como consecuencia de procesos de modernización.

Los contenidos de cada sección de este artículo se resumen a continuación.

En la sección 2 se presenta y justifica explícitamente el modelo a utilizar en este análisis. Argumentaré allí que, debido a la ausencia de otros trabajos preliminares sobre el tema, el análisis de la movilidad ocupacional intergeneracional debe restringirse, en este punto, a la primera ocupación de los entrevistados. La inclusión en el modelo de una nueva variable exógena, «cohortes de entrada en el mercado de trabajo», se justificará en base a las particularidades históricas de nuestro país. Estas particularidades hacen, cuanto menos, dudosa la utilización de efectos estructurales sin incluir cómo éstos cambiaron a lo largo del tiempo. El conjunto de hipótesis a contrastar aquí

Los pocos estudios estrictamente relacionados con la movilidad social, por ser antiguos, emplearon perspectivas teóricas y metodologías en uso en los años cincuenta y sesenta. Sólo en dos estudios (Díez Nicolás, Martínez Lázaro y Porro, 1975, y Carabaña, 1983), los autores emplearon enfoques y métodos más modernos e interesantes.

${ }^{3}$ El último trabajo empírico publicado sobre el tema data de 1983 (Carabaña), pero analiza datos correspondientes a 1975. Julio Carabaña es también autor de un estudio aún no publicado sobre «logro de estatus» en España, basado en los mismos datos que se han utilizado en esta investigación. 
sobre la relación entre cambios estructurales, oportunidades ocupacionales y el papel de la educación pondrá un punto final a la sección.

La sección 3 presenta y justifica la forma operativa de las variables a incluir en el modelo. El primer apartado se centra en la ocupación. El segundo, en la educación. El tercero y último, en las cohortes a utilizar.

En la sección 4 se presentan los datos utilizados en la investigación. Discutiremos allí los posibles efectos que los valores perdidos pueden tener sobre los resultados obtenidos.

La sección 5 presenta los resultados de este trabajo. La sección está dividida en cuatro subapartados. En el primero de ellos se analizan y comentan los resultados correspondientes al modelo tomado en su conjunto, tal y como quedará definido en la sección 3. El segundo se centra en los efectos del tiempo sobre las oportunidades educacionales de los entrevistados, y en los efectos compuestos del tiempo y de la educación sobre las primeras posiciones ocupacionales alcanzadas por los entrevistados en el mercado de trabajo. En el subapartado tercero se analizan las tendencias en la movilidad educacional y ocupacional de padres a hijos a lo largo del tiempo. Por último, en el apartado 5.4 se especifica el poder predictivo del modelo para cada una de las cohortes en que ha sido subdividida la muestra.

La última sección (sección 6) de este artículo presenta las conclusiones de este trabajo.

\section{EL MODELO DE LA INVESTIGACION}

Esta investigación pertenece a la tradición sociológica del modelo de «logro de estatus», tal y como fue definido inicialmente por Peter Blau y Otis D. Duncan en The American Occupational Structure (1967). Su modelo incluía cinco variables. Tres variables endógenas: educación, primera ocupación y ocupación actual del hijo (la última, tomada como variable dependiente; las anteriores, como variables intervinientes ordenadas temporalmente), y dos variables exógenas: educación del padre y ocupación del padre cuando el hijo cumplió los 16 años. Este modelo ha sido probado en numerosas ocasiones, en los mismos términos o en versiones modificadas que incluyen un mayor número de variables independientes. En España, dos estudios (Díez Nicolás, Martínez Lázaro y Porro, 1975; Carabaña, 1983) utilizaron este mismo marco en su diseño de investigación ${ }^{4}$.

En este estudio, basado en los datos correspondientes a una encuesta realizada por el Centro de Investigaciones Sociológicas en marzo de 19885, el

4 Es difícil, sin embargo, estimar la fiabilidad de sus resultados, dados los datos con los que trabajaron. $O$ se apoyaron en fuentes secundarias, como es el caso del primer estudio aludido, o lo hicieron en muestras restringidas diseñadas para otros propósitos, como es el caso del estudio realizado por Carabaña.

5 Véase sección 4 de este trabajo, para una descripción y discusión sobre los datos aquí utilizados. 
modelo de Blau y Duncan será modificado en dos cuestiones específicas. En primer lugar, el modelo quedará simplificado al excluir la ocupación actual del entrevistado. La variable dependiente pasará a ser «emplazamiento inicial en el mercado de trabajo», o primera ocupación. En segundo lugar, se introducirá la variable «cohorte de entrada al mercado de trabajo», a modo de indicador de los cambios estructurales habidos en el país. En lo que sigue trataré de justificar ambas decisiones.

\subsection{PRIMERA OCUPACIÓN COMO VARIABle DEPENDIENTE}

Nuestro modelo de logro de estatus excluye la ocupación actual del entrevistado. Su inclusión entrañaría serias inconsistencias lógicas, difícilmente solucionables en el marco introductorio de esta investigación. El problema principal radica en las diferencias de edad entre los entrevistados. Así, mientras para algunos entrevistados la ocupación actual puede interpretarse como la posición final alcanzada en su vida laboral, para muchos otros sólo representa un paso más en sus carreras profesionales, más cercanas a la primera ocupación cuanto más jóvenes. Hay dos soluciones que son típicas en la literatura. La primera introduce la «edad» como variable de control y analiza pautas de movilidad social dentro de grupos homogéneos de edad. La segunda utiliza «modelos de supervivencia en el tiempo» (time survival models), donde el «tiempo transcurrido en el sistema» entra en el modelo como una variable explicativa más. Ninguna de las dos será empleada aquí. En primer lugar, porque la «edad» está fuertemente correlacionada con «cohorte» si, como en esta investigación, la segunda se define a partir de la edad del entrevistado cuando consiguió su primera ocupación (véase más adelante, para más explicaciones). En segundo lugar, porque los análisis de «supervivencia» no tienen en cuenta los saltos en la probabilidad de cambiar de ocupación debidos a otros factores ajenos al tiempo (a menos que esos factores sean incluidos también en el modelo). En tercer lugar, porque la mayoría de los estudios empíricos sobre «logro de estatus» muestran que los orígenes sociales y la educación afectan las oportunidades ocupacionales fundamentalmente en el momento en que los individuos entran al mercado de trabajo por primera vez (Blau y Duncan, 1967; Featherman y Hauser, 1977; Hout, 1989). Por último, porque, al centrarnos en la primera ocupación, excluimos implícitamente otros factores que podrían influir en la movilidad de carrera, por ejemplo la experiencia laboral, o la segmentación interna del mercado de trabajo por sectores económicos, en función de las diferentes oportunidades de movilidad que cada uno de ellos provee a los trabajadores (Stinchcombe, 1979). Al excluir la ocupación actual, estoy conscientemente simplificando el análisis y haciéndolo más manejable en este punto. Lo que es más importante, estoy poniendo las bases para un análisis futuro más completo, que desglosaría la movilidad intergeneracional de padres a hijos en sus dos componentes: de la 
ocupación del padre a la primera ocupación del hijo, y de la primera ocupación a su ocupación actual.

\section{2. «COHORTE», COMO INDICADOR DEL CAMBIO SOCIAL}

Tal y como referí más arriba, estoy especialmente interesado en estudiar la relación existente entre «factores estructurales» y movilidad intergeneracional. Para clarificar lo que aquí entiendo por «factores estructurales», es necesaria una breve discusión sobre el significado que los términos «movilidad estructural» y «movilidad de intercambio» tienen en la literatura sobre la movilidad social.

Aún hoy continúa viva la polémica académica sobre el significado del término «movilidad estructural». En los últimos años, el término ha sido equiparado con la heterogeneidad observada en los marginales de una tabla de movilidad (McClendon, 1977; Sobel, 1983; Sobel, Hout y Duncan, 1985). Por «estructural» se entenderían tanto los cambios en las estructuras ocupacionales de padres e hijos como los problemas e inconsistencias lógicas que hacen dudosa esta misma interpretación ${ }^{6}$. Procedimientos de «estandarización»o «modelos logarítmicos» han sido desarrollados con el fin de separar la movilidad «estructural» de la de «intercambio» (también denominada «pura», o de «circulación»), esta última definida, más en términos estadísticos que en términos teóricos sustantivos, como la movilidad que excede de aquella movilidad estrictamente determinada por los cambios en las estructuras ocupacionales de padres e hijos?.

En contraste con esta interpretación, por «factores estructurales» entiendo aquellas circunstancias externas al individuo ${ }^{8}$ que afectan sus oportunidades de movilidad o su estatus ocupacional. Esas circunstancias pueden actuar de dos maneras: indirectamente, modificando la estructura educacional y ocupacional de una sociedad y, consecuentemente, su estructura de desigualdad, o directamente, reforzando o debilitando la relación entre los orígenes sociales del individuo y sus propios logros educacionales y ocupacionales. La primera vía se corresponde con el concepto de «movilidad estructural»; la segunda,

- Algunos de estos problemas serían: los derivados de la «selectividad» resultante de la fertilidad diferencial asociada a grupos ocupacionales de padres y de la mortalidad diferencial entre hijos; o el hecho de que las variables «ocupación del padre» y «primera ocupación del hijo» no representen estructura ocupacional alguna en un momento preciso en el tiempo, como, sin embargo, presumiblemente, sí lo haría la «ocupación actual».

7 Sobel, Hout y Duncan (1984) argumentan contra esta interpretación de la movilidad de intercambio como un «residuo». Sin embargo, su propia definición como flujos simétricos entre pares de categorías de origen y destino no aporta ningún significado teórico nuevo. McClendon (1977) ofrece otra explicación: la movilidad de intercambio se produciría como resultado de las diferencias individuales en talentos, destrezas y deseos. Opino que esta explicación carece de pruebas empíricas que la sustenten y esconde fuertes presupuestos ideológicos.

${ }^{8}$ En el sentido de pertenecer a la esfera social, no a la individual. 
con el de «movilidad de intercambio». Debería quedar claro, por lo tanto, que por factores estructurales entiendo causas estructurales, no el componente estructural de una tabla de movilidad. La industrialización, el cambio tecnológico, la transformación económica sectorial, las pautas demográficas, la profusión de medios de comunicación o las políticas gubernamentales, son algunos ejemplos de dichos «factores estructurales».

A las prácticas habituales, centradas en el estudio comparativo de la movilidad social entre distintos países, como forma de analizar los efectos de los factores estructurales sobre las oportunidades de movilidad (Lipset y Zetteberg, 1959; Blau y Duncan, 1967; Featherman y Hauser, 1977; Grusky y Hauser, $1984)^{9}$, yo replicaría señalando la dificultad que esas comparaciones entrañan, dadas las particularidades históricas de cada país. Por el contrario, comparaciones entre distintos períodos o regiones dentro de un mismo país pueden resultar mucho más informativas, aunque carezcan de la universalidad proclamada por el enfoque anterior. Este es especialmente el caso allí donde las diferencias regionales y temporales son pronunciadas, como en España ${ }^{10}$.

España es un caso único para la realización de este tipo de estudio comparativo. En los últimos treinta o cuarenta años, el país se ha visto envuelto en profundas transformaciones económicas, demográficas, sociales y políticas. Por señalar las más importantes, valga recordar las transiciones de un régimen autoritario a un régimen democrático y a un gobierno socialista; de la autarquía y el aislamiento internacional, al libre mercado y a la plena integración en la CEE; de una sociedad agrícola y tradicional, a una economía de servicios, tras un fuerte proceso de industrialización; de altas tasas de mortalidad infantil y baja esperanza de vida, a tasas de fertilidad por debajo del nivel de reemplazamiento, bajas tasas de mortalidad infantil y alta esperanza de vida; de mínimos movimientos migratorios, a fuertes migraciones internas y externas, con un retorno a la estabilidad migratoria; de altas tasas de analfabetismo, a la plena escolarización y al boom universitario ${ }^{11}$. Todos estos cambios reflejan un profundo proceso de modernización desde una sociedad tradicional hacia una sociedad «postindustrial». Ese proceso, por supuesto, aún está por terminar. Además, ha sido regionalmente dispar. Sin embargo, ha sido lo suficientemente intenso como para permitir contrastar un pequeño conjunto de interesantes hipótesis sobre la relación entre movilidad y cambio social.

La introducción de esos factores como variables independientes en el modelo de investigación resulta sumamente atrayente desde un punto de vista teórico,

"Algunas excepciones serían: el análisis de Kelley y Klein sobre Bolivia (1981) y el trabajo de Albert Simkus sobre Hungría (1984). En ambos casos, una misma sociedad es analizada bajo una perspectiva histórica.

to Las diferencias regionales no serán abordadas en este trabajo, no porque carezcan de importancia (la cuestión «regional» es fundamental para analizar la estructura social de nuestro país, tal y como ha sido puesto de relieve habitualmente por sociólogos e historiadores), sino por el carácter introductorio de este estudio.

"Véase la sección 3.3, para una más detallada descripción de estos cambios estructurales y para un elenco de las fuentes históricas utilizadas. 
pero, obviamente, difícil de realizar en el marco introductorio de esta investigación. En vez de proceder de esta forma, los cambios estructurales serán indizados mediante la construcción de cohortes históricas, que serán utilizadas como categorías de una nueva variable independiente a añadir al modelo simplificado de «logro de estatus».

En vez de emplear «cohortes de nacimiento» para capturar ese proceso de modernización, «cohorte» hará referencia aquí al período histórico en el que los entrevistados entraron por primera vez en el mercado de trabajo. En síntesis, trabajaré aquí con cohortes definidas por la primera ocupación. Puesto que estamos fundamentalmente interesados en explicar los primeros logros ocupacionales de los entrevistados por los cambios estructurales ocurridos en el país, el tiempo histórico en que esos cambios (y consecuentes logros ocupacionales) se fraguaron adquiere gran relevancia teórica, comparado con otros «tiempos» alternativos e importantes de la propia biografía del entrevistado, como su fecha de nacimiento o la fecha en que cumplió los 25,35 o cuales. quiera otros años de edad.

\subsection{EL MODELO Y LAS HIPÓTESIS}

El modelo, tal y como ha sido esbozado más arriba, puede representarse mediante el siguiente diagrama causal.

\section{DIAGRAMA 1}

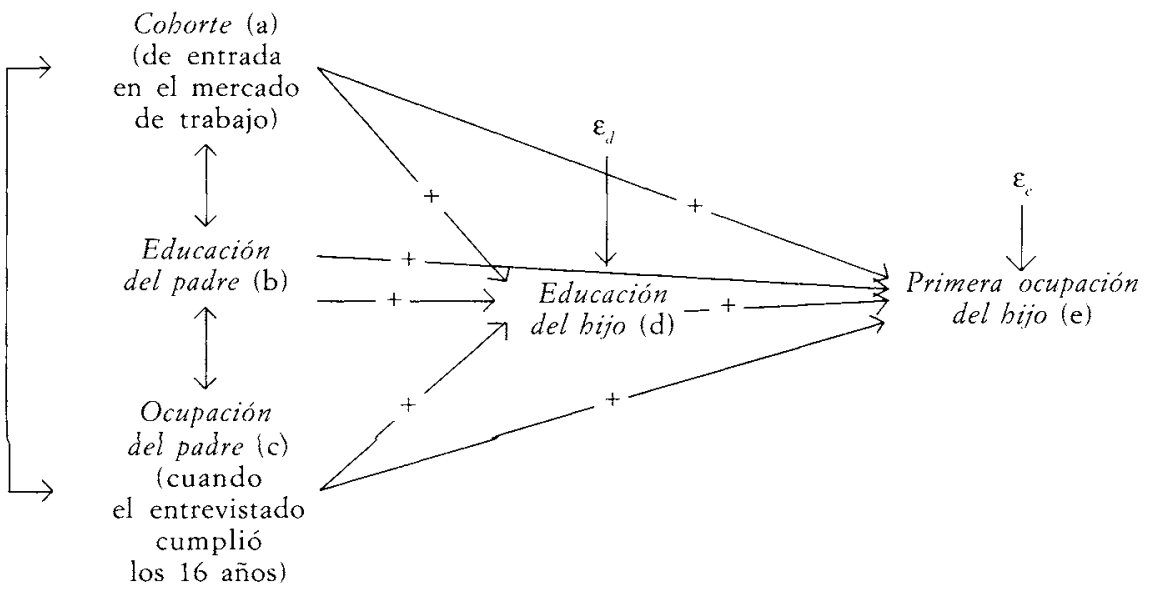


En el modelo se establece la hipótesis de que la educación y la ocupación del padre afectan directa e indirectamente (a través de sus efectos sobre los logros educacionales del hijo ${ }^{12}$ ) la posición ocupacional que el hijo alcanzará al ingresar en el mercado de trabajo. Los signos positivos sobre las flechas indican que la relación se cree positiva, de manera que cuanto más altos sean los orígenes sociales del hijo, más altas esperamos que sean sus oportunidades ocupacionales.

Las flechas positivas que conectan «Cohorte» con «Educación del hijo» y «Primera ocupación del hijo» simbolizan la siguiente hipótesis: el proceso de modernización en el que España se ha visto envuelta en las últimas décadas habría tenido el efecto global de incrementar la probabilidad de que los entrevistados ingresen en niveles más altos de la estructura ocupacional. Este efecto sería tanto directo como indirecto. Este último, incrementando los recursos educativos a su disposición.

Ateniéndonos a una interpretación estricta de la variable «Cohorte», ésta debería afectar solamente a la variable dependiente, esto es, a la primera ocupación. «Cohorte» está por «año de entrada en el mercado de trabajo»y, por lo tanto, indicaría, para gran parte de los entrevistados, un período posterior al transcurrido en la escuela, el instituto o la universidad. Sin embargo, dada la proximidad temporal entre ambos momentos y dado el contenido que hemos asignado a la variable «Cohorte», como representación de un proceso continuo de modernización, esta variable debería afectar también a los logros educacionales de los entrevistados. Por ejemplo, animándolos a interrumpir sus estudios y a aceptar un trabajo en tiempos de prosperidad económica, o a continuar esos estudios en tiempos de recesión. Debido a la ambigüedad de estos factores, deberemos ser cautos a la hora de interpretarlos.

Para estudiar estos efectos me serviré de una representación continua de la variable cohorte, basada en la fecha (año) de entrada de los entrevistados en el mercado de trabajo $^{13}$. La nueva variable será utilizada como un índice de modernización. Fechas más tardías indicarían una mayor modernización.

Esta representación continua dificulta, sin embargo, el estudio de los efectos que determinados factores estructurales, o combinaciones específicas de ellos, han tenido en las oportunidades de movilidad social de los españoles. De hecho, al proceder de esta manera asumimos que el ritmo de modernización y sus efectos sobre los logros educativos y ocupacionales de los entrevistados fueron constantes a lo largo del tiempo. Si es importante obtener una medida global y genérica de la relación entre movilidad y cambio social, aún lo es más el determinar los puntos de ruptura - si los hubo-y las causas que están tras ellos. Con este fin, la representación continua de la variable «cohorte»

12 De aquí en adelante utilizaremos a menudo la expresión «hijo» para teferirnos al entrevistado. Recuérdese que los datos correspondientes a los padres son los referidos por los entrevistados, es decir, por sus hijos.

is La variable fue construida sumando la edad de entrada en el mercado de trabajo a la fecha de nacimiento, que, a su vez, fue deducida de la edad actual del entrevistado y de la fecha de realización de la entrevista (1988). 
ha sido quebrada en distintos intervalos o períodos históricos homogéneos ${ }^{14}$. Basándonos en esta clasificación, intentaremos determinar la dirección, la intensidad y el ritmo de los cambios experimentados en la relación entre orígenes sociales y logros educativos y ocupacionales, asociándolos a, o explicándolos por, el contexto histórico (político, económico, social) en el que se produjeron.

La mayor parte de los estudios sobre pautas de movilidad social asocian su volumen a procesos de industrialización, movilidad geográfica, urbanización y desarrollo educativo. En Opportunity and Change (1978: 13), Featherman y Hauser sintetizan ese desarrollo teórico listando un conjunto de hipótesis que ligan el volumen de la movilidad de intercambio (movilidad neta) al grado de desarrollo de cada uno de esos factores. Cuanto más altos sean éstos, mayor sería aquélla. Blau y Duncan (1967), por su parte, describen la tendencia histórica de la movilidad social en los Estados Unidos como el paso de un modelo de «adscripción» a un modelo de «logro» de estatus: los orígenes sociales, medidos por los logros educativos y ocupacionales de los padres, habrían perdido importancia en la determinación de los logros sociales (educativos, ocupacionales) de sus hijos. Las posiciones ocupacionales de los hijos dependerían hoy mucho más de sus propios logros educacionales que de las posiciones ocupacionales de sus padres, y esos logros educacionales se habrían producido con (mayor) independencia de los logros educacionales de sus padres. Por último, Jenks (1972) relativiza estas tendencias enmarcándolas dentro de un proceso histórico de crecimiento de la desigualdad social, entendiendo por tal una mayor dispersión o diferenciación ocupacional.

Es este conjunto de teorías e hipótesis el que me propongo explorar en este trabajo, tomando como base la comparación entre cohortes (períodos) de pautas de movilidad y cambios en el modelo de «logro de estatus» presentado más arriba.

\section{LAS VARIABLES}

\subsection{LA OCUPACIÓN DEL PADRE Y LA PRIMERA OCUPACIÓN DEL HIJO}

Como es habitual en los estudios de movilidad social, las ocupaciones fueron codificadas, en los datos que estoy analizando, utilizando la versión española a tres dígitos de la Clasificación Internacional de Ocupaciones ( $\mathrm{Cla}$ sificación Nacional de Ocupaciones, CNO, INE, 1980), que es la fuente para clasificar las ocupaciones en cada Censo. La recodificación de estas ocupaciones en un número razonable de categorías es una de las posibles alternativas para reducir ese volumen de información. La otra alternativa pasa por ordenar las ocupaciones en una escala jerárquica y utilizar esta última como variable

${ }^{1+}$ En la sección 3.3 de este trabajo se presentan estos períodos y se justifica su elección. 
continua. En ambos casos, el problema teórico principal es el de decidir entre criterios alternativos para recodificar u ordenar las ocupaciones. Esto implica dos pasos previos. Primero, la formulación de los intereses teóricos del investigador, es decir, qué pretende medir: clases sociales (Clogg, 1981; Wright, 1985; Breiger, 1981, 1990), estatus socioeconómico (Feldman y Tumin, 1961; Duncan, 1964) o representaciones populares del prestigio social (Siegel, 1971; Treiman, 1975, 1977). Y segundo, una asunción o hipótesis sobre la forma concreta que ese fenómeno exhibe en la sociedad: jerarquías continuas (Feldman y Tumin, 1961; Duncan, 1964; Treiman, 1975, 1977), configuraciones topológicas (Breiger, 1981; Clogg, 1981) o ambas (Featherman y Hauser, 1977; Erikson y Goldthorpe, 1987a, 1987b). La complejidad de estas cuestiones, y la imposibilidad de resolverlas de forma satisfactoria en este punto, me convencieron de la necesidad de confiar en algún estudio previo que me permitiera trabajar con una representación fiable del standing ocupacional de padres e hijos en España ${ }^{15}$.

La Escala Internacional Estandarizada de Prestigio Ocupacional (EIEPO), o Standard International Occupational Prestige Scale, construida por Donald J. Treiman en 1975 y revisada por él mismo en 1977, ha sido utilizada aquí con este propósito. En esta escala, a cada una de las ocupaciones recogidas a tres dígitos en la Clasificación Internacional de Ocupaciones - de la que la versión española difiere levemente- le fue asignada una puntuación, de 0 a 100 , que reflejaría su prestigio medio entre 55 países, incluyendo España ${ }^{16}$. Trabajos anteriores habían mostrado una gran consistencia y estabilidad, tanto entre países como a lo largo del tiempo, en las representaciones populares del prestigio ocupacional. En este momento es difícil determinar si esas características son o no aplicables a España. La única evidencia a nuestra disposición avalaría la primera interpretación ${ }^{17}$. La adaptación específica de la EIEPO de Treiman a España es obra de Julio Carabaña (1989, sin publicar), quien empleó los mismos datos que los utilizados en esta investigación. La adaptación entraña pequeñas modificaciones en la escala de Treiman, con vistas a maximizar el detalle con el que algunas ocupaciones fueron recogidas en la encuesta.

Algunos críticos de la utilización, en un análisis de movilidad, de escalas subjetivas para ordenar jerárquicamente las ocupaciones argumentan que este tipo de escalas explicaría una menor proporción en la asociación (varianza)

$15 \mathrm{La}$ ausencia en nuestros datos de información correspondiente a los ingresos de los entrevistados y al prestigio social asociado por ellos a cada ocupación imposibilita la construcción de un índice socioeconómico de ocupaciones en España, a la manera en que Duncan (1964) lo ideó para los Estados Unidos. La inclusión de esos datos en otros estudios realizados posteriormente despeja el camino para hacerlo en el futuro.

is La versión española de la escala de prestigio de Siegel (NORC), utilizada por Treiman para la elaboración de la EIEPO, fue realizada por Amando de Miguel en 1967. Incluye sólo un pequeño subconjunto del total de ocupaciones recogidas a tres dígitos en la CNO y está basada en una muestra de jóvenes españoles.

17 Aun manteniendo ciertas reservas derivadas de las restricciones en los objetivos y en la muestra del estudio realizado por Amando de Miguel. 
entre orígenes y destinos que índices socioeconómicos construidos por el investigador. Tal y como subraya Jencks (1990), estos críticos olvidan lo que aquellas escalas pretenden medir, algo diferente a lo reflejado por los índices socioeconómicos pero, aun así, «fenómenos sociales reales». En concreto, las escalas de Siegel o Treiman miden representaciones sociales del prestigio ocupacional. La escala de Duncan, el standing socioeconómico de esas ocupaciones.

Otros críticos, centrándose en el carácter continuo de aquellas escalas (incluyendo los índices socioeconómicos), argumentan que la asunción de una distancia social constante entre posiciones ocupacionales carece de fundamento, y que las representaciones continuas ocultan aspectos importantes del proceso de estratificación en las sociedades modernas, a saber, su articulación en clases sociales. Coincidiendo básicamente con esta interpretación, opino, sin embargo, que, en el punto introductorio en el que nos encontramos, las ventajas de utilizar una escala continua exceden en mucho a sus inconvenientes. Teniendo presente lo que la escala de Treiman refleja, su configuración continua simplifica enormemente el análisis estadístico, reduciendo el número de coeficientes a analizar.

Por último, cabría señalar los graves inconvenientes de utilizar una escala de prestigio como la de Treiman, considerablemente insensible a variaciones a lo largo del tiempo, para medir los cambios ocurridos en la estructura ocupacional, más aún cuando nuestro interés principal está en explicar esos cambios por las transformaciones estructurales habidas en el país. Creo que esta insensibilidad del «artefacto» ha podido afectar las magnitudes absolutas (y, posiblemente, la significación) de los coeficientes y estadísticos presentados en la sección 5. Considero, sin embargo, que el indicador refleja adecuadamente, aunque con menor detalle, la dirección, el ritmo e incluso la intensidad de esos cambios, siempre y cuando tomemos los resultados en su contexto relativo (comparativo), ya sea en relación a los períodos de tiempo analizados, ya sea respecto a los componentes de movilidad analizados.

\subsection{LA EDUCACIÓN DEL PADRE Y DEL HIJO}

La educación del padre y del hijo fueron originariamente codificadas como variables nominales. Esto es, no hay información directa sobre el número de años correspondientes a cada nivel. Sin embargo, las variables recogen información pormenorizada sobre los niveles educativos alcanzados por padres e hijos. Cambios en niveles y grados derivados de la reforma de 1970 fueron en gran parte recogidos mediante su inclusión como categorías diferentes. En general, la traducción en años entre antiguos y nuevos niveles educativos no ofrece mayores complicaciones ${ }^{18}$. Una versión comprimida de esta

18 Sin embargo, tal y como Arnold S. Feldman y yo mismo hemos podido observar al estudiar los datos correspondientes a otra encuesta posterior realizada por el CIS, 
variable, válida para todos los entrevistados (y para sus padres), se presenta más abajo (a). Los valores entre paréntesis reflejan los códigos en la variable original (b), que se reproduce a continuación.

Versión recodificada (a)

Código original (b)

I) Analfabetos (1).

II) Menos de 6 años de escuela (2).

III) Primer grado. 6-8 años de escuela $(3,4,5)$.

IV) Segundo grado. 10-12 años de escuela (6).

V) Escuela Universitaria. 12-15 años (7).

VI) Facultad o ETS. 16-18 años (8).

VII) Postgrado (Master, Doctor, Especialista). Más de 18 años (9).
1) Analfabetos.

2) Menos de 6 años de escuela.

3) Estudios primarios (Plan antiguo: primaria terminada; Nuevo plan: no terminó $\mathrm{EGB}$ ).

4) EGB terminada.

5) Bachillerato Elemental.

6) Bachiller Superior, BUP, COU.

7) Grado Medio, Escuelas Universitarias.

8) Facultad o ETS.

9) Estudios de Postgrado.

10) Otros.

Como en el caso de la ocupación, en esta investigación la educación será tratada como variable continua. Puesto que no existe información directa sobre el número de años de estudio, asignaremos puntuaciones a cada una de las siete categorías de la versión (a), que neutraliza o «controla» los posibles cambios en el sistema educativo. Con las puntuaciones, de 1 a 7 , asumimos que los niveles están espaciados de forma constante, tanto en el tiempo como en su dificultad, o en las recompensas sociales asociadas a ellos. En la práctica, este procedimiento presupone una relación lineal entre logros educacionales y ocupacionales ${ }^{19}$. Otra limitación de este método es que no tiene en cuenta las diferencias cualitativas entre tipos de certificaciones (títulos) e instituciones (privadas o públicas, por ejemplo). La ausencia de datos sobre estas cuestiones explica esta simplificación. Este método representa un compromiso entre las teorías del «capital humano» y las teorías «credencialistas». Por un lado, las puntuaciones no representan años de estudio, como hubiera sido el caso de haber estimado el número de cursos correspondiente a cada nivel. Por el otro,

existen algunos problemas relativos al nivel de «Primaria», anterior a la LGE de 1970. Según nuestros resultados preliminares, la equiparación de «Primaria» con «EGB»es, cuando menos, problemática, pues la mayor parte de los entrevistados que refieren estudios primarios no completaron los ocho cursos que, oficialmente, constituían ese nivel. Para evitar confusiones, a los entrevistados clasificados en primaria les han sido asignados de seis a ocho años de escuela. Posteriormente fueron agrupados junto a las categorías 4 y 5 del código original (véase más arriba).

19 Jencks (1972: 160) resume los resultados de investigaciones previas sobre las consecuencias de asumir linealidad en un análisis de movilidad. Su conclusión es que esta asunción apenas afecta a los resultados. Winship y Mare (1984) discrepan de esta interpretación, mostrando cómo una asunción «logarítmica» o «normal» para la relación entre la educación del padre y la del hijo, además de ser sustantivamente mucho más atractiva, ajusta mejor la nube de puntos (respuestas) a la función estimada. 
como ya señalábamos, al emplear esas puntuaciones asumimos que las dificultades y recompensas son constantes entre niveles.

\subsection{Cohorte DE ENTRADA EN EL MERCADO DE TRABAjO}

En la sección 2.3 de este artículo apuntábamos la necesidad de quebrar la representación continua de la variable «cohorte» para estudiar los efectos de factores estructurales específicos sobre las oportunidades de movilidad de los entrevistados. Criterios históricos, en vez de estadísticos, han sido empleados para distinguir seis cohortes relevantes de entrada en el mercado de trabajo. Se corresponden con los siguientes períodos: 1) hasta 1940; 2) 1941-1951; 3) $1952-1961$; 4) $1962-1974$; 5) $1975-1982$; 6) $1983-1987$. En el cuadro 1 intento poner de relieve las características principales de cada uno de estos períodos. Para su realización, y para la creación misma de la variable «cohorte», han sido consultadas distintas fuentes secundarias ${ }^{20}$.

Los períodos han sido construidos buscando maximizar su homogeneidad en relación a los factores estructurales en los que estoy interesado ${ }^{21}$. Claramente, esto es sólo parcialmente posible, pues no todos esos factores pueden ser asimilados a períodos históricos concretos y exclusivos. No obstante, creo que esta categorización describe fehacientemente el compás del cambio social en España desde la guerra civil.

Las tendencias descritas en el cuadro 1 deben interpretarse como variaciones intraperíodos, no como magnitudes absolutas, o como variaciones entre períodos. Por ejemplo, el signo de igualdad para el período 1983-87 y el nivel educativo superior reflejaría un volumen constante en el número de estudiantes matriculados en ese nivel al principio y al final de ese período. El volumen total es, sin embargo, alto, tan alto como el alcanzado al final del período $1975-82$.

${ }^{20}$ La información sobre la situación política proviene fundamentalmente de Carr (1982), Moreno (1990) y Tamames (1988); los datos económicos, de Abad y Delgado (1990), Cuadrado (1990), García Delgado (1990), Harrison (1985), Hernández (1990), Lieberman (1982), Ministerio de Trabajo y Seguridad Social (1986), Myro (1990), Pedreño (1990), Pérez Yruela (1990), Segura (1990), Tamames (1988), Tezanos (1990) y Vázquez (1990); la información sobre movimientos migratorios y procesos de urbanización, de Díez Nicolás (1990); las pautas educativas, de Carabaña (1989, sin publicar), INE (1970) y McNair (1984).

${ }^{21}$ En esta fase de la investigación restringiremos nuestro análisis al período histórico posterior a la guerra civil. La cohorte anterior a 1940 será utilizada exclusivamente a efectos comparativos, como kilómetro cero de nuestro recorrido histórico. Los resultados correspondientes a esta cohorte deben interpretarse con cautela, más como punto de referencia que como indicativos de las características de la cohorte, dada la heterogeneidad en la edad de los entrevistados comprendidos en ella. La fecha media de entrada en el mercado de trabajo está, para esos entrevistados, en torno a 1932, con una desviación típica de 7,1 años y un rango de 32 años (de 1908 a 1940). En consecuencia, obviaremos cualquier análisis descriptivo de esta cohorte, a la que, repetimos, corresponden marcadas diferencias históricas. 


\section{CUADRO 1}

Evolución de los principales factores estructurales

\begin{tabular}{|c|c|c|c|c|c|}
\hline & $1941-51$ & $1952-61$ & $1962-74$ & $1975-82$ & $1983-87$ \\
\hline Situación política & $\begin{array}{l}\text { Dictadura. } \\
\text { Represión. } \\
\text { Autarquía. }\end{array}$ & $\begin{array}{l}\text { Dictadura. } \\
\text { Reconocimiento } \\
\text { inernacional } \\
\text { (Vaticano, EE.UU., } \\
\text { ONU, FMI, } \\
\text { OCDE). }\end{array}$ & $\begin{array}{l}\text { Dictadura. } \\
\text { Tímida } \\
\text { liberalización } \\
\text { (Ley Prensa). } \\
\text { Tecnocracia. }\end{array}$ & $\begin{array}{l}\text { Transición } \\
\text { democrática. } \\
\text { Constitución. } \\
\text { Monarquía. } \\
\text { OTAN. }\end{array}$ & $\begin{array}{l}\text { Consolidación } \\
\text { democrática. } \\
\text { Gob. Socialista. } \\
\text { CEE. } \\
\text { OTAN. }\end{array}$ \\
\hline $\begin{array}{l}\text { Ciclos economicos } \\
\text { (basado en \% } \triangle \text { PIB, IPC } \\
\text { y desempleo) }\end{array}$ & $\begin{array}{l}\text { Recesivo. } \\
\text { Racionamiento. } \\
\text { «Extraperlo». }\end{array}$ & $\begin{array}{l}\text { Moderadamente } \\
\text { expansivo } \\
\text { (excepto Plan } \\
\text { de Estabilización). }\end{array}$ & $\begin{array}{l}\text { Fuertemente } \\
\text { expansivo. }\end{array}$ & $\begin{array}{l}\text { Recesivo. } \\
\text { Crisis del petróleo } \\
\text { (73 y 79). }\end{array}$ & $\begin{array}{l}\text { Moderadamente } \\
\text { expansivo } \\
\text { (a partir de 1984). }\end{array}$ \\
\hline $\begin{array}{l}\text { Cambios sectoriales } \\
(\% \text { PIB y \% población activa) }\end{array}$ & & & & & \\
\hline - Agricultura & $=$ & -- & --- & -- & - \\
\hline - Industria & $=$ & + & ++ & - & $=$ \\
\hline $\begin{array}{l}\text { - Servicios } \\
\text { Urbanización } \\
\text { (\% de población en ciudades }\end{array}$ & $=$ & + & ++ & ++ & ++ \\
\hline $\begin{array}{l}\text { de } 100.000 \text { habilantes y más) } \\
\text { Migraciones }\end{array}$ & $=$ & + & +++ & + & + \\
\hline - Internas (salcto interprov.) & $=$ & ++ & $+t+$ & $=$ & $=$ \\
\hline $\begin{array}{l}\text { Externas } \\
\text { Educación (matriculados) }\end{array}$ & + & ++ & $+t+$ & -- & - \\
\hline - Primaria & $=$ & + & +++ & + & $=$ \\
\hline - Secundaria & + & ++ & +++ & + & $=$ \\
\hline - Superior & + & + & ++ & +++ & +++ \\
\hline
\end{tabular}

Simbolos: = sin cambios; - suave saldo negativo; - - moderado saldo negativo; - - - fuerte saldo negativo; + suave saldo positivo; ++ moderado saldo positivo; +++ fuerte saldo positivo. Los simbolos reflejan «saldos intraperíodos», es decir, ratios entre las magnitudes finales e iniciales en cada periodo. 


\section{LOS DATOS}

Los datos que utilizaré en esta investigación pertenecen a una macroencuesta $(N=27.377)$ llevada a cabo en marzo de 1988 por el Centro de Investigaciones Sociológicas, a cuya dirección agradezco desde aquí el que pusiera a mi disposición tan importante fuente de información. El universo estuvo constituido por todos los ciudadanos españoles mayores de 18 años. La muestra fue estratificada por regiones y tamaño de hábitat. La selección final de los entrevistados se llevó a cabo mediante el sistema de «rutas aleatorias» y siguiendo cuotas preestablecidas de sexo y edad. El corazón de la encuesta fue diseñado fundamentalmente para obtener datos sobre las actitudes políticas de los españoles, pero se añadió una sección especial para recoger información sobre los historiales ocupacionales y educativos de los entrevistados. En esa sección se recogió información detallada sobre la educación, situación de mercado actual y primera y última ocupación del entrevistado (incluyendo el sector económico correspondiente a esas ocupaciones). Datos adicionales sobre la educación del padre y sobre la ocupación del padre cuando el entrevistado cumplió los 16 años completan esa información.

No todas las entrevistas serán utilizadas en esta investigación. En primer lugar, todas las mujeres han sido excluidas del análisis. Su exclusión se justifica por la ausencia de datos inequívocos sobre sus ocupaciones ${ }^{22}$ y por las incongruencias derivadas de utilizar información sobre el padre como punto de partida de las trayectorias de movilidad de sus hijas. Su inclusión implicaría probablemente la utilización de distinta metodología, lo que complicaría en exceso esta investigación.

En segundo lugar, sólo los varones que hayan trabajado en algún momento de sus vidas serán incluidos en el análisis. Este hecho puede afectar la fíabilidad de los estadísticos obtenidos para la cohorte más joven, puesto que al excluir a parte de esos entrevistados (a los que ingresaron en el mercado de trabajo a edades más jóvenes) tenderemos a sobrerrepresentar las ocupaciones para cuyo ejercicio se requiere una mayor formación educativa (un mayor número de años estudiando).

Finalmente, y a diferencia de una gran parte de los estudios realizados sobre movilidad social que restringen la muestra a la población actualmente activa, en este trabajo incluiremos tanto a los desempleados como a los jubilados que hayan trabajado antes. La elección de la primera ocupación como variable dependiente en el modelo de esta investigación explica esta decisión.

La aplicación de estas restricciones produjo un fuerte recorte en el número de entrevistas a analizar, que baja de 27.377 a 11.653 . Pero no todos los entrevistados contestaron a todas las preguntas pertinentes. Sólo 4.342 lo hicieron. Aun así, este número constituye la mayor muestra jamás utilizada en España en un análisis de movilidad social. La decisión de excluir las entrevis-

22 Sobre todo, por la conocida temporalidad e irregularidad del trabajo femenino hasta fechas recientes. 
tas que figuran como «valores perdidos» o «no contesta» en una o en más de una de las variables incluidas en el modelo se debe, fundamentalmente, a criterios de fiabilidad ${ }^{23}$ y a razones técnicas ${ }^{24}$.

Más importante que el intentar recuperar las «no respuestas» es el determinar la influencia o posible sesgo que su exclusión pueda tener en los resultados.

De los 7.311 entrevistados que no contestaron a alguna de las cinco preguntas incluidas en nuestro modelo, 6.400 , o el 88 por 100 , no lo hicieron a sólo una de ellas; 5.864 de entre estos últimos, o el 92 por 100, no contestaron a nuestra variable dependiente, es decir, a la primera ocupación. Resumiendo, el 80 por 100 de las no respuestas en nuestro modelo de investigación se concentran en la variable dependiente (primera ocupación).

Si los entrevistados que no contestan a esta pregunta tuvieran perfiles similares, en términos de sus respuestas a las variables explicativas del modelo, a los que sí lo hicieron, su exclusión en nada afectaría a los resultados de nuestros análisis. En ese caso, la probabilidad de contestar a la primera ocupación (o, alternativamente, de no hacerlo) sería aleatoria. Lo contrario no produciría necesariamente un sesgo en los resultados. En regresión lineal, la técnica estadística en la que nos basaremos en este trabajo, asumimos que los valores de nuestras variables independientes están fijos, y que para cada valor definido por la intersección entre ellas, el error $^{25}$ se distribuye de forma aleatoria, con media igual a 0 , y dispersión constante (que los errores son «homoesquedásticos», utilizando la expresión anglosajona). Si la probabilidad de contestar o no a la primera ocupación fuera sólo una función de las variables independientes de nuestro modelo, esas asunciones seguirían sosteniéndose. Ahora bien, si aquella probabilidad dependiera también del error incluido en nuestra ecuación de regresión ${ }^{26}$, entonces el valor esperado de nuestro término de error, condicionado al valor tomado por las variables independientes, dejaría de ser igual a 0 . En esas condiciones, el método ordinario de ajuste de la recta de regresión mediante mínimos cuadrados produciría parámetros sesgados e ineficientes.

${ }^{23}$ Aunque existen sofisticados procedimientos estadísticos, como el análisis discriminante, para asignar valores a las no respuestas, sus resultados siguen descansando en «suposiciones», no en obscrvaciones. Esas técnicas asignan respuestas a los individuos «perdidos» en función de la similitud de sus respuestas a otras preguntas, a las que sí contestaron, con las respuestas de otros individuos que contestaron a todas ellas. Si, como aquí (véase más adelante), el subgrupo de entrevistados que contestan a la/s variable/s de interés no difiere acusadamente del subgrupo de los que no lo hacen, la asignación de respuestas a los «valores perdidos» mediante la utilización de esos procedimientos no añadiría información alguna al análisis, dejando inalterados los resultados obtenidos con el subgrupo de entrevistas completas.

${ }^{2+}$ Tal y como se verá en la sección 5 , este trabajo se apoya fundamentalmente en técnicas de regresión y correlaciones entre variables. Aunque casi todos los paquetes estadísticos ofrecen la oportunidad de maximizar el número de entrevistas a utilizar (por ejemplo, el método pairwise en el SPSS), analizando por pares un conjunto de preguntas, estos procedimientos impiden la realización de valiosos tests de significación (los denominados tests $F$ de incremento en la varianza explicada).

${ }^{25}$ Los factores o variables no tenidos en cuenta en la estimación.

${ }^{26} \mathrm{Si}$ el error estuviera correlacionado con las variables independientes. 
Si analizar las diferencias estadísticas entre entrevistas válidas y no válidas respecto a sus valores en las variables explicativas del modelo no entraña demasiada dificultad, probar que el error es independiente de los valores tomados por las variables explicativas es tarea ardua y difícil ${ }^{27}$, y excede de mis pretensiones. Por lo tanto, me conformo aquí con analizar las diferencias entre los que contestan y callan a la variable dependiente, en función de sus respuestas a las variables independientes.

En términos estadísticos, el problema radica en determinar si para individuos con distintos valores en las variables explicativas del modelo, cualesquiera que éstos puedan ser, la razón entre los que contestan y callan a la variable dependiente permanece constante, cualquiera que sea su magnitud. Por lo tanto, nuestra tarea inmediata consiste en contrastar la hipótesis nula de que la probabilidad de contestar a la primera ocupación, en relación con la de no contestar, es independiente del origen social (ocupación y educación del padre), de la fecha de entrada en el mercado de trabajo y del currículum educacional del entrevistado.

Para contrastar esta hipótesis nula de independencia estadística hemos utilizado un modelo $\log i t^{28}$. Básicamente, se trata de una técnica de regresión ${ }^{29}$ donde la variable dependiente, cualitativa, con sólo dos valores $(0$ : no contestó; 1: contestó a la primera ocupación), una vez transformada en razón, es explicada por un conjunto de variables independientes; en nuestro caso, por todas las variables explicativas incluidas en el modelo de la investigación. Para cada nivel de las variables independientes, los valores predichos por la ecuación de regresión representan el logaritmo natural de la proporción de entrevistados que contestó a la primera ocupación en relación a los que no lo hicieron. Si esa proporción, interpretada en términos de probabilidad, fuera independiente de las variables explicativas, debería alcanzar un valor constante y, por lo tanto, todos los coeficientes correspondientes a las variables explicativas no deberían alcanzar la significación. Cualquier desvío respecto al modelo de independencia vendría señalado por la significación en uno o en varios de esos coeficientes. Con esta técnica, además de probar el modelo general de independencia, conseguiremos identificar las causas, aisladas en los efectos significativos de las variables independientes, que explican cualquier posible desvío en ese modelo general. La tabla 1 presenta los coeficientes resultantes de la

27 Un método ingenioso para detectar y corregir este problema ha sido desarrollado por el econometrista James Heckman (1987). Para una introducción al problema y una presentación de las últimas técnicas disponibles para su corrección, véase Mare y Winship (1991, aún sin publicar).

28 No es éste el lugar para detenernos en la explicación de los modelos logarítmicos (modelos genéricos de asociación entre variables), entre los cuales habría que incluir los modelos logit. Para lectores en inglés recomiendo el libro de Alan Agresti (1990), excelente, aunque requiere conocimientos estadísticos previos. Una introducción sencilla, aplicada a las tablas de movilidad, está disponible en Michael Hout (1983).

24 Aunque la estimación de los coeficientes se realiza por el método de máxima verosimilitud, en vez de por el de mínimos cuadrados. 


\section{TABLA 1}

Análisis de valores perdidos. Regresión logística sobre las variables explicativas del modelo

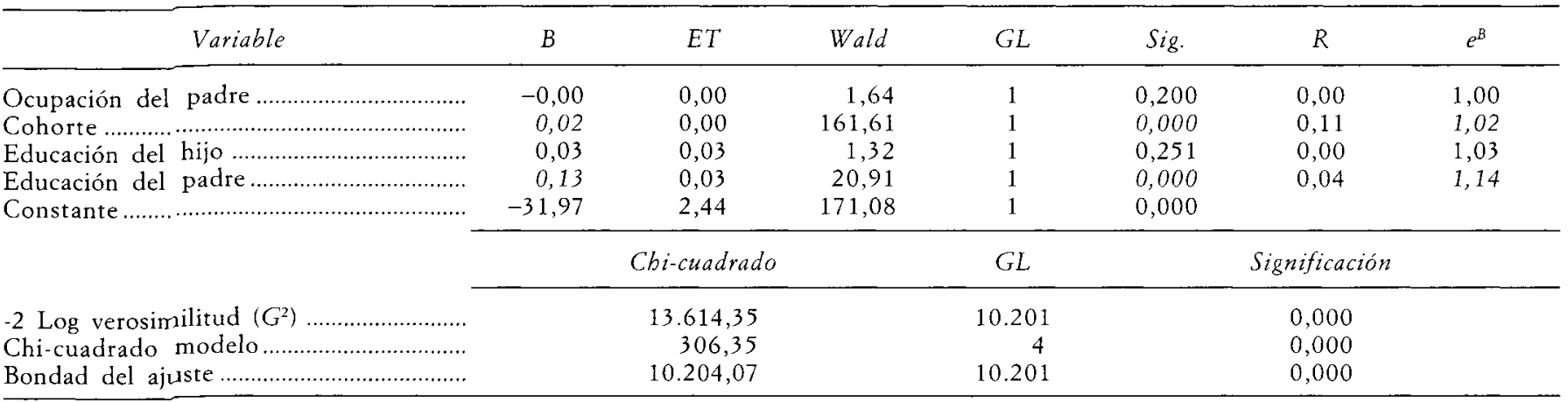

B: Parámetros o coeficientes estimados.

ET: Error típico estimado para los coeficientes o parámetros $B$

Wald: Ratio entre el parámetro estimado y su error típico estimado.

GL: Grados de libertad.

Sig.: Significación.

$R$ : Contribución de la variable independiente a la explicación de la variable dependiente.

$e^{B}$ : Cambio en la probabilidad (razón) de contestar respecto a la de no contestar a la primera ocupación.

-2 Log verosimilitud $\left(G^{2}\right)$ : Contrasta la hipótesis nula de que los datos estimados no difieren de los observados.

Chi-cuadrado modelo: Contrasta la hipótesis nula de que todos los coeficientes son iguales a 0.

Bondad del ajuste: Medida del ajuste del modelo. 
regresión logística, así como su significación estadística (al nivel del 0,05$)$ y otros estadísticos pertinentes.

Centrándonos primero en los niveles de significación de los parámetros estimados, los resultados muestran que el logaritmo natural de la razón de los que contestaron a los que no lo hicieron varía significativamente en función del año de entrada de los entrevistados en el mercado de trabajo y del nivel educativo de sus padres. Cuanto más reciente sea aquél y más alto sea éste, mayor es la probabilidad de que el entrevistado conteste a la primera ocupación (respecto a la de no contestar). Sin embargo, esta razón crece lentamente, indicando que las diferencias entre ambos grupos, aunque significativas, apenas deberían afectar los resultados obtenidos con el subgrupo de entrevistas válidas. Esta interpretación resulta avalada por la ausencia de un buen ajuste del modelo ${ }^{30}$. Las probabilidades estimadas por los parámetros del modelo y las observadas en los datos son significativamente diferentes. El modelo tiende a (se equivoca al) clasificar a los que sí contestaron como no respuestas ${ }^{31}$, porque en ese segmento de la muestra se encontrarían aún muchos entrevistados de edades más altas y cuyos padres presentan niveles educativos inferiores, para quienes se predicen menores índices de respuesta. En definitiva, conocer cuándo se incorporó el entrevistado al mercado de trabajo y cuál es su nivel educativo en poco ayuda a predecir su disposición a contestar a la primera ocupación. Nuestra conclusión es que ambos grupos de entrevistados son básicamente homogéneos respecto a las variables explicativas del modelo y que, en consecuencia, la exclusión de las no respuestas no afectará la fiabilidad de los resultados obtenidos con el subgrupo de respuestas válidas.

Con este análisis damos por terminada la presentación de las hipótesis y teorías, así como de los datos sobre los que se basa esta investigación. El resto del artículo estará dedicado a presentar y comentar los resultados.

\section{RESULTADOS}

\subsection{El MODELO COMPLETO}

El diagrama 2 presenta los coeficientes estandarizados (en mayor tamaño) y no estandarizados (en menor tamaño y entre paréntesis), derivados de regresar, por el método ordinario de mínimos cuadrados $\left(\mathrm{OL}{ }^{32}\right)$, la primera ocupación del hijo $\left(X_{5}\right)$ sobre las variables intervinientes $\left(X_{4}\right)$ y exógenas $\left(X_{1}, X_{2}\right.$ y $X_{3}$ ) del modelo, y de regresar la educación del hijo $\left(X_{4}\right)$ sobre esas mismas variables exógenas $\left(X_{1}, X_{2}\right.$ y $\left.X_{3}\right)$.

30 Véanse las tres últimas filas de la tabla 1.

31 En concreto, el modelo predice acertadamente un 82 por 100 de las no respuestas, pero sólo un 27 por 100 de las respuestas a la primera ocupación.

${ }^{32}$ Del inglés Ordinary Least Squares. A lo largo de esta sección daremos explicaciones puntuales sobre posibles violaciones de las asunciones de la OLS y las medidas tomadas para remediarlas. 


\section{DIAGRAMA 2}

Conjunto de la muestra

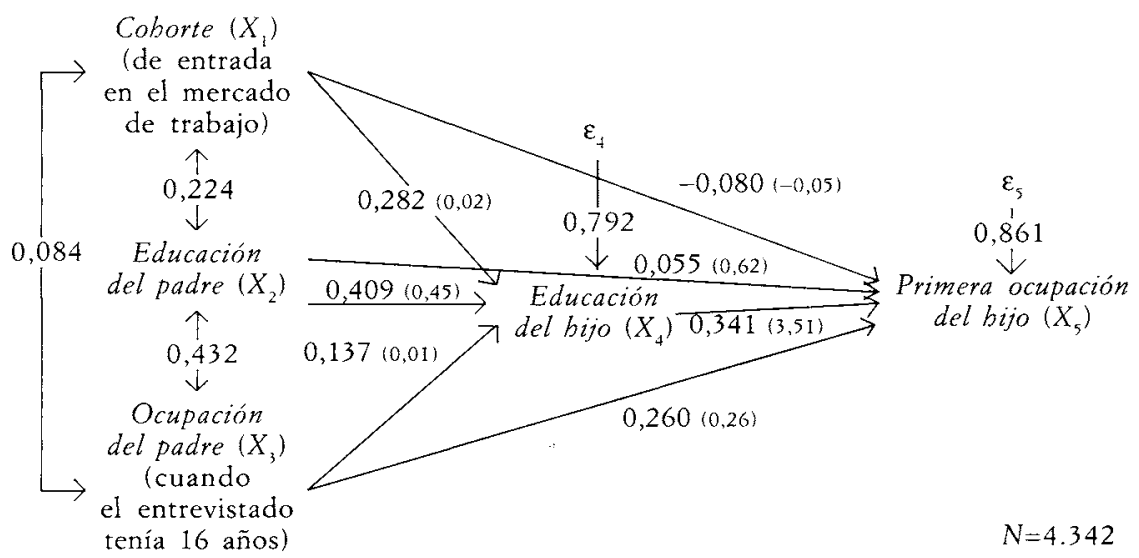

Todos los coeficientes son significativos al nivel 0,05 (95 por 100). Los coeficientes no estandarizados son más eficaces para expresar leyes causales y comparar poblaciones, porque no dependen de la varianza específica de las variables (Blalock, 1971). Utilizaremos estos coeficientes cuando comparemos los resultados obtenidos para cada cohorte. Por el contrario, los coeficientes estandarizados $^{33}$, o betas, llamados coeficientes de camino cuando forman parte de un modelo causal como el que estamos analizando, son más apropiados para describir relaciones en poblaciones particulares, ofreciendo una estimación de la fuerza relativa y de la dirección de los efectos causales de las variables explicativas sobre la variable dependiente.

Otra ventaja del análisis de camino es que permite descomponer el efecto total de una variable exógena en sus distintos componentes: efectos directos e indirectos. En el diagrama 2, las flechas que van directamente de $X_{1}, X_{2}$ y $X_{3}$ a $X_{5}$ representan los efectos directos de las variables exógenas sobre la primera ocupación. Por ejemplo, el efecto directo de la educación del padre sobre la primera ocupación del hijo, cuando el resto de factores causales se mantienen constantes, es igual a 0,260 . Esto es, la ocupación del padre afecta positivamente las primeras oportunidades ocupacionales de sus hijos ${ }^{34}$.

33 Los coeficientes estandarizados se obtienen al multiplicar los coeficientes brutos estimados por la ecuación de regresión (coeficientes no estandarizados) por la desviación típica de la variable explicativa, y dividiendo después por la desviación típica de la variable dependiente. Por lo tanto, indican el cambio, en unidades de desviación típica de la variable dependiente, que habría que esperar por cada cambio unitario en la desviación típica de la variable independiente (Hanushek y Jackson, 1977).

${ }^{34}$ Los coeficientes no estandarizados resaltan mejor la relación causal: 0,26 representaría el cambio esperado (otros factores mantenidos constantes) en las 
Pero la ocupación del padre también tiene un efecto indirecto sobre la primera ocupación del hijo, al afectar positivamente $(0,137)$ sus oportunidades educativas, que, a su vez, afectan positivamente $(0,341)$ sus propios logros ocupacionales. El efecto indirecto de la ocupación del padre sobre la primera ocupación del hijo viene dado, simplemente, por el producto de estos dos coeficientes de camino $(0,137 \times 0,341=0,047)^{35}$. Su efecto total, por la suma de sus efectos directos e indirectos $(0,260+0,047=0,307)$. Los coeficientes en las flechas de dos puntas que conectan las variables exógenas entre sí son los coeficientes de correlación de Pearson: indican la asociación entre las variables exógenas, una asociación que no se pretende explicar causalmente. $\varepsilon_{4}$ y $\varepsilon_{5}$ representan los términos de error en las dos ecuaciones del modelo. Los coeficientes situados en las flechas que unen estos términos de error con las variables endógenas expresan la porción de estas variables que, en términos de su correlación con las variables independientes, ha quedado «inexplicada» ${ }^{36}$. Al elevar al cuadrado esos valores, obtenemos la misma porción pero esta vez expresada en términos de varianza ${ }^{37}$. Así, el 74 por $100\left(0,861^{2}=0,742\right)$ de la

puntuaciones de los hijos en la escala ocupacional de Treiman, por cada cambio unitario en las puntuaciones de los padres en esa escala. A los hijos de padres con puntuaciones bajas se les predicen bajas puntuaciones. Cuanto más alto sea el prestigio ocupacional de los padres, más alto esperamos que sea el prestigio ocupacional de sus hijos.

${ }^{35}$ Para verlo más claro, considere las dos ecuaciones que definen el modelo:

$$
\begin{aligned}
& X_{5}=p_{51} X_{1}+p_{52} X_{2}+p_{53} X_{3}+p_{54} X_{4}+\varepsilon_{5}=-0.080 X_{1}+0,055 X_{2}+0,260 X_{3}+0,341 X_{4}+\varepsilon_{5} \\
& X_{4}=p_{41} X_{1}+p_{42} X_{2}+p_{43} X_{3}+\varepsilon_{4}=0.282 X_{1}+0,409 X_{2}+0,137 X_{3}+\varepsilon_{4}
\end{aligned}
$$

Sustituyendo la ecuación [2] en la [1], obtenemos:

$$
\begin{gathered}
X_{5}=p_{51} X_{1}+p_{52} X_{2}+p_{53} X_{3}+p_{54}\left(p_{41} X_{1}+p_{42} X_{2}+p_{43} X_{3}+\varepsilon_{4}\right)+\varepsilon_{5}= \\
=\left(p_{51}+p_{54} p_{41}\right) X_{1}+\left(p_{52}+p_{54} p_{42}\right) X_{2}+\left(p_{53}+p_{54} p_{43}\right) X_{3}+p_{54} \varepsilon_{4}+\varepsilon_{5}= \\
=\phi_{51} X_{1}+\phi_{52} X_{2}+\phi_{53} X_{3}+\mu
\end{gathered}
$$

Denominaremos a esta última expresión como la forma reducida de la ecuación, donde:

$$
\begin{aligned}
& \phi_{53}(\text { Total })=p_{53}(\text { directo })+p_{54} p_{+3}(\text { indirecto })=-0,260+(0,341) \quad(0,137)=0,307 \\
& \phi_{51}=p_{51}+p_{5+1} p_{41}=-0,080+(0,341) \quad(0,282)=0,016 \\
& \phi_{52}=p_{52}+p_{54} p_{42}=0,256+(0,341) \quad(0,409)=0,395
\end{aligned}
$$

36 El valor exacto se obtiene sustrayendo de 1 el correspondiente $R^{2}$ (proporción de varianza explicada) y extrayendo la raíz cuadrada de este resultado.

3 El coeficiente de determinación $\left(R^{2}\right)$ varía entre 0 y 1 . Si es igual a 1 , significa que el modelo explica el cien por cien de la variación en la variable dependiente. Si es igual a 0 , el modelo no explica nada de esa variación. Normalmente, el $R^{2}$ es interpretado como una medida de la bondad del ajuste. Tal y como señala Christopher $\mathrm{H}$. Achen (1982), otras medidas, como el error típico de la regresión, pueden ofrecer mejores estimaciones de ese ajuste (véase tabla 2 en este apartado). El error típico de la regresión expresa, en las unidades de medida de la variable dependiente, lo lejos que están, en promedio, los valores observados de la variable dependiente de sus valores estimados $\left[\mathrm{ET}=\sqrt{ } \Sigma e^{2} / N-k-1\right.$, donde $\Sigma e^{2}$ es el sumatorio de los residuos (diferencia entre los valores observados de la variable dependiente y los estimados por la ecuación de regresión) elevados al cuadrado, $N$ es el número de individuos en la muestra, y $k$ el número de coeficientes incluidos en la ecuación]. Este estadístico nos será de gran utilidad al 
varianza en la primera ocupación del entrevistado queda inexplicada por nuestro modelo o, alternativamente, el modelo explica el 26 por 100 de esa varianza $^{38}$. La proporción total de varianza explicada puede descomponerse en partes, que reflejarian tanto la contribución de cada variable independiente a la explicación de la variable dependiente como aquella porción de varianza explicada que no puede ser atribuida a ninguna de ellas tomadas individualmente, sino a grupos de variables tomados en conjunto. El análisis de la varianza es un pobre instrumento para determinar el efecto causal de las variables explicativas si se comparan distintas muestras, pues, como en el caso de las betas, el $R^{2}$ varía en función de las varianzas de esas variables. Si dividimos la muestra por cohortes y aplicamos el modelo a cada una de ellas, los cambios en el $R^{2}$ pueden ser simplemente debidos a los cambios en aquellas varianzas, no a cambios en el poder predictivo del modelo.

Podemos avanzar ya una interpretación del diagrama 2, centrándonos primero en los coeficientes de camino y, después, en la proporción de varianza explicada. Contrariamente a lo que esperábamos, la variable Cohorte, que interpretamos como un indice de modernización, tiene un efecto negativo, pero pequeño, sobre las primeras oportunidades ocupacionales de los entrevistados: cuanto más cercana sea la fecha de su entrada en el mercado de trabajo, más bajo será su estatus ocupacional ${ }^{39}$. Sin embargo, nótese que «Cohorte» tiene un efecto indirecto positivo $(0,096)$ sobre la ocupación de los hijos, al incrementar sus logros educativos. Su efecto total es positivo $(0,016)$, aunque muy pequeño ${ }^{40}$. Señalábamos antes que el efecto de la cohorte sobre la

comparar los resultados correspondientes a las distintas cohortes, pues tiene la ventaja de que no depende, como el $R^{2}$, de la varianza de las variables independientes.

38 ¿Cómo deberíamos interpretar esta magnitud? ¿Es pequeña o grande? Una forma de contestar a estas preguntas consiste en comparar nuestro resultado con los obtenidos en otros contextos. Al extraer la raíz cuadrada de la proporción de varianza explicada $(00,26=0,51)$, obtenemos una estimación de la correlación entre las variables independientes y la variable dependiente del modelo. Tal y como se recoge en Kelley y Klein (1981), un ejemplo clásico sobre la correlación entre padres e hijos, para determinados rasgos transmitidos genéticamente, como la altura, la establece en torno a 0,5 . La correlación entre el coeficiente intelectual de padres e hijos está también próxima a 0,5 . Art Stinchcombe opina que estas correlaciones tienden a sobreestimar la asociación genética entre padres e hijos: la correlación entre el coeficiente intelectual de esposos y esposas, y de madres e hijos, es también cercana a 0,5 .

${ }^{39} \mathrm{La}$ ecuación de regresión predice que, por cada año de retraso en la incorporación al mercado de trabajo, los entrevistados bajarán, por término medio, 0,080 puntos en la escala Treiman.

${ }^{40}$ Una inspección gráfica de los residuos estandarizados por cohortes me hizo sospechar que podría existir un problema de «heteroesquedasticidad» (distinta varianza de los errores para distintos valores de las variables independientes). Para contrastar esta hipótesis reestimé las regresiones: a) con el método de mínimos cuadrados ponderados (WLS), utilizando las desviaciones típicas para cada año en la variable cohorte como pesos; y b) mediante el método OLS, transformando logarítmicamente las variables. En ambos casos, los coeficientes betas permanecieron estables, excepto los correspondientes a los efectos de la cohorte sobre la educación del hijo, que aumentaron a 0,342 y 0,334 , respectivamente. Sin embargo, también el coeficiente correspondiente al efecto de la educación del hijo sobre la primera ocupación se vio afectado, descendiendo a 0,260 al 
educación del hijo debería ser interpretado con cautela, puesto que, para gran parte de la muestra, indicaría fechas en las que los entrevistados habrían finalizado ya sus estudios. Escribíamos entonces que, en la medida en que la Cohorte refleje un proceso continuo de modernización, debería ser considerada todavía como un indicador fiable de los efectos de esa modernización sobre las oportunidades educacionales de los entrevistados. Para corroborar esta hipótesis hemos contrastado una réplica del modelo original, donde la fecha de entrada en el mercado de trabajo ha sido sustituida por la fecha en la que el entrevistado cumplió los 16 años ${ }^{41}$. Los coeficientes correspondientes a la nueva variable son similares a (no son significativamente diferentes de) los obtenidos para nuestra variable original (Cohorte): 0,127, para el efecto directo sobre la primera ocupación, y 0,235 , para el efecto sobre la educación.

El efecto directo más alto sobre la primera ocupación es atribuido en nuestro modelo original a la ocupación del padre $(0,260$, comparado con un 0,055 para la educación del padre). Sin embargo, es la educación del padre la que tiene un efecto indirecto $(0,140$, contra 0,047) y un efecto total $(0,395$, contra 0,307 ) mayores sobre aquella variable, dada su fuerte influencia en la educación del hijo. Los resultados apoyan la tesis de que el estatus del padre, definido por su currículum ocupacional y educativo, se transmite con fuerza sobre sus hijos, a través de procesos de inmovilidad educativa y ocupacional. La educación del hijo contribuye poderosamente a explicar sus propios logros ocupacionales y representa una importante variable interviniente en aquel proceso de transmisión intergeneracional de estatus, sobre todo en lo que respecta a las cualificaciones educativas del padre.

Si prestamos atención ahora al análisis de la varianza explicada ${ }^{42}$, veremos que sus resultados confirman parcialmente los obtenidos con anterioridad. La tabla 2 presenta los $R^{2}$ y los errores típicos de las regresiones, así como los resultados correspondientes a la descomposición de la varianza en sus distintos componentes ${ }^{43}$.

emplear variables logarítmicas, lo que confirma la sospecha de que la relación entre las dos variables podría ser curvilínea. En estas estimaciones, el test de Breusch-Pagán para detectar «heteroesquedasticidad» se mantuvo significativo (como en la primera estimación con OLS), aunque los $X^{2}$ se redujeron drásticamente. Los resultados de estos tests muestran que este problema no es achacable al efecto de una única variable explicativa, sino al de todas (o grupos de) ellas.

41 Una forma aún más consistente de contrastar esta hipótesis consistiría en incluir esta nueva variable en el modelo original, junto con la variable Cohorte. Sin embargo, tanto la antigua como la nueva variable estarían fuertemente correlacionadas entre sí, produciendo lo que se denomina «multicolinealidad»; por tanto, restando precisión y fiabilidad a los coeficientes obtenidos.

+2 Es costumbre en el análisis de camino el determinar la contribución de las variables independientes a la explicación de la variable dependiente mediante la descomposición de los coeficientes de correlación. Por el contrario, aquí utilizaremos el método más extendido de descomposición del $R^{2}$, empleando tests de incremento $\mathrm{F}$ para contrastar su significación.

${ }^{4}$ Para llevar a cabo esta descomposición se ha empleado el método de «asignación jerárquica» (Draper y Smith, 1966), que asigna las porciones compartidas por las variables exógenas y la variable endógena enteramente a las primeras (puesto que así lo refleja 
TABLA 2

Proporción (\%) de varianza explicada: modelo completo

\begin{tabular}{|c|c|c|c|c|c|c|}
\hline \multirow[b]{2}{*}{ Variable dependiente } & \multicolumn{3}{|c|}{ Primera ocupación bijo } & \multicolumn{3}{|c|}{ Educación del bijo } \\
\hline & $\% R^{2}$ & $F$ & Sig. & $\% R^{2}$ & $F$ & Sig. \\
\hline Total $R^{2}$ & 25,617 & 373,4 & 0,000 & 38,921 & 921,4 & 0,000 \\
\hline Exógenas... & 18,726 & 333,2 & 0,000 & 38,921 & 921,4 & 0,000 \\
\hline$X_{1}(\mathrm{a})$ & 0,023 & 1,212 & 0,271 & 8,287 & 588,6 & 0,000 \\
\hline Orígenes sociales ......... & 17,984 & 479,9 & 0,000 & 22,760 & 808,3 & 0,000 \\
\hline$X_{2}$ (b) & 2,997 & 160,0 & 0,000 & 13,265 & 942,1 & 0,000 \\
\hline $\mathrm{X}_{3}^{2}$ (c) $\ldots \ldots \ldots \ldots \ldots \ldots \ldots \ldots \ldots \ldots \ldots \ldots$ & 7,657 & 408,7 & 0,000 & 1,537 & 109,1 & 0,000 \\
\hline Compartido (1) (d) & $7,330^{*}$ & & & $7,958 *$ & & \\
\hline Compartido (2) (e).... & $0,719 \div$ & & & $7,874 *$ & & \\
\hline Endógena $\left(X_{4}\right)(\mathrm{f}) \ldots \ldots \ldots$ & 6,891 & 401,8 & 0,000 & & & \\
\hline Error tipico $(\sigma)$ & 9,572 & & & 0,795 & & \\
\hline
\end{tabular}

$X_{1}=$ Cohorte $X_{2}=$ Educación del padre $X_{3}=$ Ocupación del padre $X_{4}=$ Educación del hijo Compartido (1)=Porcentaje $R^{2}$ compartido (explicado conjuntamente) por $X_{2}$ y $X_{3}$. Compartido (2)=Porcentaje $R^{2}$ compartido por $X_{1}, X_{2}$ y $X_{3}$, menos porcentaje compartido en exclusiva por $X_{2}$ y $X_{3}$.

*=Porcentaje calculado indirectamente, mediante sumas o restas de cantidades estimadas directamente con anterioridad.

(a), (b), (c), (d), (e), (f)=Véase figura 1 .

Una vez descompuesta la varianza en aquellos componentes, obtenemos una visión más clara de la contribución individual (o conjunta) de las variables. La figura que se presenta a continuación pretende ayudar al lector a identificar esos elementos. En la figura no se pretende reproducir exactamente

nuestro modelo causal). En la práctica se regresa primero la variable dependiente sobre las tres variables exógenas (es decir, se excluye a la educación del hijo). El $R^{2}$ así obtenido representa el total de varianza explicada atribuible a las variables exógenas. Para descomponer esta porción en contribuciones individuales (independientes), se regresa la variable dependiente sobre, alternativamente, las tres posibles combinaciones de las variables exógenas tomadas de dos en dos (por ejemplo, $X_{5}$ sobre $X_{2}$ y $X_{3}$ ). La diferencia entre el $R^{2}$ obtenido para la ecuación que incluye a todas las variables exógenas (1) y el $R^{2}$ obtenido para la ecuación que incluye a sólo dos de ellas (2) nos proporciona la varianza explicada atribuible en exclusiva a la variable excluida de la ecuación 2 (en el ejemplo, a $X_{1}$ ). Para saber si esta porción es significativa o no se realizan tests $\mathrm{F}$ de incremento en la varianza explicada (de los que el lector puede encontrar referencias en la mayoría de manuales básicos de estadística). Si lo que se desea es conocer la parte atribuible a un subconjunto de variables exógenas (a los «orígenes sociales», por ejemplo) se procede de igual forma, sólo que, en vez de excluir a una sola variable de la ecuación 2 , se excluye a todas las del subconjunto. Además, la diferencia en el $R^{2}$ obtenido para este subconjunto y el obtenido para las variables individuales que lo forman nos proporciona la porción de varianza explicada conjuntamente (compartida) por ellas. Por último, para conocer qué parte de varianza explicada corresponde a la variable interviniente (educación del hijo) hay, primero, que regresar la variable dependiente sobre el conjunto de variables independientes $\left(X_{1}, X_{2}, X_{3}\right.$ y $\left.X_{4}\right)$ y restar del $R^{2}$ así obtenido el correspondiente a la regresión de $X_{5}$ sobre $X_{1}, X_{2}$ y $X_{3}$. 
el peso relativo de cada componente identificado en la tabla 2 , sino clarificar los conceptos con los que estamos trabajando.

\section{FIGURA 1}

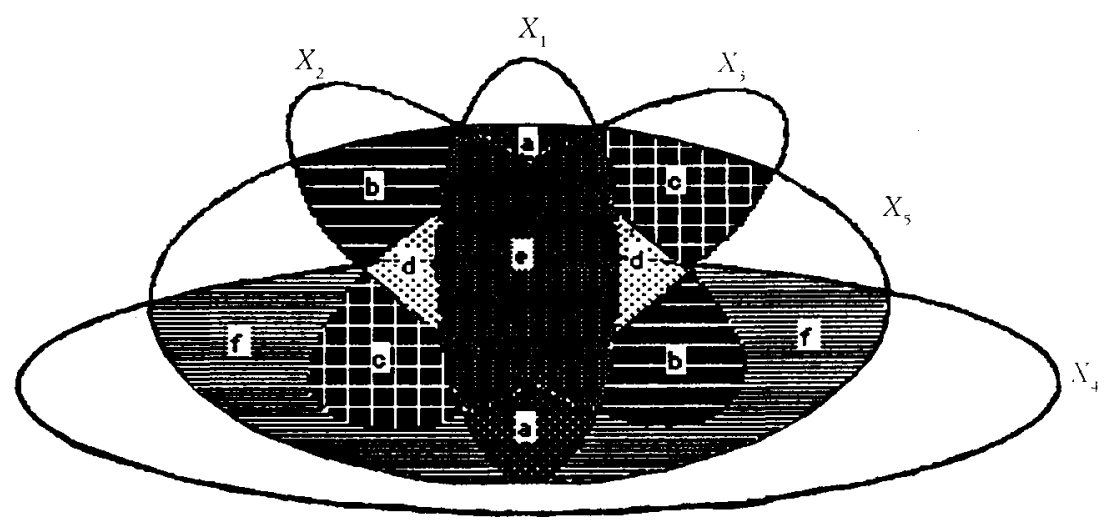

Las variables exógenas, ya sea mediante contribuciones individuales o compartidas entre ellas, explican cerca del 19 por 100 de la varianza de la primera ocupación, bastante más que la variable endógena (la educación del hijo) por sí sola. Esta contribución es atribuible casi en su totalidad (18 por 100) a los efectos de los orígenes sociales (educación+ocupación del padre). Entre éstas, y a nivel individual ${ }^{44}$, es con mucho la ocupación del padre la variable que mayor porporción de varianza explica de la primera ocupación del hijo. Este resultado debe analizarse con cautela, dada la magnitud del componente compartido (explicado conjuntamente) por ellas ( 8 por 100). El efecto de la cohorte, por su parte, es pequeño (como vimos al analizar el efecto total de sus coeficientes en el diagrama 2) y no significativo. En definitiva, son los orígenes sociales de los entrevistados los que mejor explican la variación en sus estatus ocupacionales, aunque la educación mantiene una importancia considerable.

Si consideramos ahora a la educación del hijo como variable dependiente, encontramos que el orden de importancia entre las variables se ha invertido. Es ahora la educación del padre la que presenta el mayor peso explicativo individual, mientras que la ocupación del padre ocupa el último lugar, por

${ }^{44}$ Utilizamos aquí el término «individual» para expresar la proporción de varianza explicada que puede atribuirse en exclusiva a cada variable explicativa. La proporción total es mayor que la proporción individual, pues parte de los efectos de la variable se transmiten a través de su relación con el resto de variables explicativas (porciones «compartidas» en la tabla 2). Esto es válido sólo para las variables exógenas, en tanto en cuanto cualquier porción compartida por la variable endógena y las variables exógenas ha sido asignada por entero a estas últimas (véase nota anterior). 
detrás, incluso, de la cohorte. Nótese que el componente compartido por las variables que definen a los orígenes sociales es relativamente pequeño; no así el correspondiente a la relación entre la cohorte y los orígenes sociales, que aumenta considerablemente. Globalmente, el conjunto de variables independientes explican un 39 por 100 de la varianza de la educación del hijo, bastante más que la correspondiente a la primera ocupación (26 por 100 $)^{45}$.

Resumiendo, aun debiendo ser cautos al interpretar los resultados, debido a la gran cantidad de varianza explicada atribuible a los efectos conjuntos de las variables exógenas, el análisis de la varianza tiende a confirmar las pautas observadas en el análisis de los coeficientes de camino, en lo que se refiere a sus efectos totales. Las contribuciones de la cohorte y de la educación del padre se materializan principalmente en la determinación de los logros educacionales de los entrevistados. Las de la ocupación del padre y de la educación del hijo, en sus logros ocupacionales. Los orígenes sociales (educación+ocupación del padre) se constituyen en el factor explicativo más importante de las diferencias entre los estatus ocupacionales de los entrevistados, aunque los niveles educativos por ellos alcanzados mantienen una contribución neta considerable. El tiempo, interpretado como un indicador de los cambios estructurales, concentra sus efectos sobre los logros educacionales del entrevistado, incrementando, tal y como muestra el coeficiente de camino, las oportunidades educativas de la población. El análisis de la configuración histórica de esta tendencia, así como de los cambios que la modernización haya podido producir en los efectos del resto de las variables del modelo, forman el núcleo de las próximas secciones de este trabajo.

\subsection{LOS EFECTOS DEL TIEMPO SOBRE LAS OPORTUNIDADES EDUCATIVAS Y OCUPACIONALES DE LOS ENTREVISTADOS}

En vez de estimar una ecuación de regresión para cada cohorte, a fin de estudiar los cambios en los efectos de las variables explicativas sobre la primera ocupación, hemos optado aquí por emplear el método dummy, que permite hacerlo con una sola ecuación. En ésta, junto a las variables explicativas originales (excepto la «cohorte»), aparecen tantas variables binarias $(0,1)$ como cohortes distinguimos en la sección 3.3, y tantos términos de interacción como los resultantes de multiplicar cada una de estas variables binarias por las variables explicativas originales (excepto para el período anterior a 1941, que representa la categoría base con la que el resto de cohortes se comparan). Este método proporciona estimaciones más precisas de los coeficientes (al aumentar los grados de libertad) e indica claramente si las diferencias entre períodos se deben a cambios en las pendientes, en las constantes o en las dos. Si hubiera

45 El error típico de la regresión, expresado ahora en unidades educacionales (tal y como han sido definidas en esta investigación), es pequeño, indicando un buen ajuste del modelo. 
cambios en las constantes, los coeficientes para las cohortes en cuestión serían significativos, lo que indicaría un incremento o descenso en las oportunidades ocupacionales (o educacionales, con la educación del hijo como variable dependiente) de los entrevistados, con respecto al período anterior a 1941. Si hubiera cambios en las pendientes, el término de interacción correspondiente al período y a la variable explicativa analizados sería también significativo, indicando que su efecto sobre la variable dependiente es diferente al que tenía en el período anterior a 1941. La tabla 3 presenta los resultados de esta regresión.

Los coeficientes no estandarizados (b) de las tres primeras variables de la tabla $3 \mathrm{~A}$ y de las dos primeras de la tabla 3B expresan los efectos de las variables explicativas sobre la correspondiente variable dependiente en el período anterior a 1941. Los coeficientes correspondientes a las variables 4 a 8 en la tabla $3 \mathrm{~A}$ ( 3 a 7 en la tabla 3B) representan los efectos de cada cohorte sobre las variables dependientes, es decir, cambios en las constantes. El resto de coeficientes reflejan la interacción entre cada una de las cohortes y la ocupación del padre, la educación del padre y la educación del hijo (esta última, sólo en la tabla 3A), es decir, cambios en las pendientes. A partir del error típico de los coeficientes $\left(2 .^{a}\right.$ columna) podemos calcular intervalos de confianza al nivel $0,05\left(3 .^{a}\right.$ y $4 .^{a}$ columnas) y contrastar posibles diferencias entre períodos en sus efectos, además de las relativas al período anterior a 1941.

Centrándonos primero en los cambios en las constantes, los resultados muestran cómo los cambios estructurales habidos en el país han hecho descender gradualmente las oportunidades ocupacionales iniciales de los entrevistados. Recuérdese que éste es un efecto neto, es decir, independiente de otras posibles causas incluidas en el modelo, y que, por lo tanto, no refleja ganancias o pérdidas individuales finales ${ }^{46}$. Es sorprendente, al menos, que el período inmediatamente posterior a la guerra civil (1941-1951) presente el mayor efecto positivo (y directo) sobre esas oportunidades ocupacionales $(+1,84)$, en relación al período precedente ${ }^{47}$. En conjunto, el período que comprende la dictadura (1941-1974) tiene un impacto positivo, aunque la tendencia es a declinar según transcurre el tiempo. Nótese que ninguno de los coeficientes para ese período son significativamente diferentes del efecto implícito para el período anterior a 1941. La tendencia es, sin embargo, muy consistente. Sólo después de la reinstauración de la democracia (1975), el efecto del «tiempo»,

46 De hecho, tal y como se verá más adelante, la puntuación media de la primera ocupación en la escala de Treiman ha crecido ligeramente durante el período analizado.

${ }^{47} \mathrm{La}$ fuerte demanda de trabajo cualificado y semicualificado, debida a los efectos de la guerra civil (150.000 muertos y 300.000 expatriaciones, según las fuentes más conservadoras) y de la represión subsecuente (entre 100.000 y 200.000 ejecuciones, dependiendo de las fuentes, más 75.000 ó 300.000 encarcelamientos) (Tamames, 1986), podrían explicar este efecto positivo tan alto sobre las oportunidades ocupacionales de los entrevistados que ingresaron en el mercado de trabajo en ese decenio (muchos de ellos, siguiendo este discurso, podrían haber salido muy beneficiados de su alineamiento con el Frente Nacional). 
TABLA 3

Resultados de la regresión correspondiente al modelo de cobortes

A) Variable dependiente: ocupación del hijo

\begin{tabular}{|c|c|c|c|c|c|c|c|}
\hline \multirow{2}{*}{$\frac{\text { Variable }}{\text { 1. Ocupación del padre...... }}$} & \multirow{2}{*}{$\frac{b}{0,32}$} & \multirow{2}{*}{$\frac{E T}{0,04}$} & \multicolumn{2}{|c|}{$\begin{array}{c}\text { Intervalos } \\
\text { de confianza }\end{array}$} & \multirow{2}{*}{$\frac{\text { Betat }}{0,32}$} & \multirow{2}{*}{$\frac{T}{8,70}$} & \multirow{2}{*}{$\frac{\text { Sig. } T}{0,000}$} \\
\hline & & & 0,24 & 0,39 & & & \\
\hline 2. Educación del padre ...... & 1,15 & 0,54 & 0,08 & 2,21 & 0,10 & & 0,035 \\
\hline 3. Educación del hijo ........... & 2,53 & 0,51 & 1 , & 3 , & 0,23 & 4,94 & 0,000 \\
\hline 4. Cohorte $1941.51 \ldots$ & 1,84 & 2,11 & $-2,3$ & 5 , & 0,06 & 0,87 & 0,383 \\
\hline 5. Cohorte 1952-61 & 0,91 & 2,18 & $-3,36$ & 5,18 & 0,03 & 0,42 & 0,677 \\
\hline 6. Cohorte 1962-74. & 0,14 & 1,84 & $-3,46$ & 3,75 & 0,01 & 0,08 & 0,938 \\
\hline 7. Cohorte 1975-82 & $-4,20$ & 2,09 & $-8,30$ & $-0,09$ & $-0,15$ & $-2,01$ & 0,045 \\
\hline 8. Cohorte 1983-87 & $-7,82$ & 2,57 & $-12,87$ & $-2,78$ & $-0,20$ & $-3,04$ &, 002 \\
\hline $51 \times$ Ocu. padre ......... & 0,01 & 0,05 & $-0,09$ & 0 , & 0,01 & 0,17 & 0,866 \\
\hline 10. C52-61xOcu. 1 & $-0,07$ & 0 & $-0,17$ & 0,03 & $-0,09$ & $-1,40$ & 0,162 \\
\hline 11. $62-74 \times$ Ocu. padre ........ & $-0,09$ & 5 & $-0,18$ & $-0,00$ & - & -1 & 0,050 \\
\hline $2 \times O_{c u}$ padre ......... & $-0,11$ & 5 & 1 & $-0,01$ & -0 & -2 &, 035 \\
\hline 13. $\mathrm{C} 83$ & 0,01 & 0 & 1 & 0 & 0 & 1 & 917 \\
\hline 14. $\mathrm{C} 41$ & $-0,48$ & 0,77 & $-1,98$ & 1, & -0 & - & 0,535 \\
\hline 15. C52-61XEdu. $\mathrm{P}$ & $-0,69$ & 0,74 & $-2,1$ & 0,76 & $-0,06$ & $-0,93$ & 0,351 \\
\hline 16. C62-74xEdu. padre ........ & $-0,47$ & 0,66 & $-1,76$ & 0,83 & $-0,05$ & $-0,71$ & 0,479 \\
\hline 17. C75-82xEdu. padre ..... & $-0,30$ & 0,71 & $-1,68$ & 1,0 & $-0,03$ & $-0,43$ & 0,670 \\
\hline 18. C83-87 XEdu. padre ..... & $-0,62$ & 0,76 & -2 , & 0 , & $-0,05$ & $-0,81$ & 0,416 \\
\hline 19. C41.51 $\times$ Edu. hijo ............. & $-0,12$ & 0,75 & $-1,59$ & 1 & $-0,01$ & $-0,16$ & 0,87 \\
\hline 20. C52-61xEdu. hijo. & 1,33 & 0,70 & $-0,05$ & 2, & 0,14 & 1,90 & 0,058 \\
\hline 21. C62-74xEdu. hijo............ & 1,10 & 0,62 & $-0,12$ & 2,31 & 0,15 & 1,77 & 0,076 \\
\hline 22. C75 & 2,10 & 0,64 & 0,84 & 3,36 & 0,28 & 3,28 & 0,001 \\
\hline 23. C83-87xEdu. hijo .......... & 2,06 & 0,75 & 0,60 & 3,52 & 0,22 & 2,77 & 0,006 \\
\hline Constante ...... & 13,32 & 1,45 & 10,48 & 16,15 & & 9,20 & 0,000 \\
\hline
\end{tabular}

B) Variable dependiente: educación del hijo

\begin{tabular}{|c|c|c|c|c|c|c|c|}
\hline 1. Ocupación del padre.... & 0,01 & 0,00 & 0,01 & 0,02 & 0,16 & 3,56 & 0,000 \\
\hline 2. Educación del hijo ......... & 0,55 & 0,04 & 0,47 & 0,62 & 0,50 & 14,05 & 0,000 \\
\hline 3. Cohorte 1941-51. & 0,36 & 0,16 & 0,04 & 0,67 & 0,13 & 2,24 & 0,025 \\
\hline 4. Cohorte 1952-61 ............ & 0,60 & 0,16 & 0,28 & 0,92 & 0,21 & 3,66 & 0,000 \\
\hline 5. Cohorte $1962-74 \ldots \ldots \ldots \ldots$ & 0,58 & 0,14 & 0,31 & 0,85 & 0,25 & 4,15 & 0,000 \\
\hline 6. Cohorte 1975-82. & 1,00 & 0,16 & 0,70 & 1,31 & 0,38 & 6,46 & 0,000 \\
\hline 7. Cohorte 1983-87 .............. & 1,21 &, 19 & 0,85 & 1,57 & 0,34 & 6,58 & 0,000 \\
\hline 8. C41-51×Ocu. padre ........ & $-0,00$ & 0,00 & $-0,01$ & 0,01 & $-0,02$ & $-0,32$ & 0,75 \\
\hline 9. C52-61 $\times$ Ocu. padre ....... & $-0,00$ & 0,00 & $-0,01$ & 0,01 & $-0,02$ & $-0,37$ & 0,712 \\
\hline 0. C62-74xOcu. padre ......... & 0,01 & 0,00 & $-0,00$ & 0,01 & 0,10 & 1,52 & 0,12 \\
\hline 1. C75-82xOcu. padre ........ & 0,00 & 0,00 & $-0,01$ & 0,01 & 0,04 & 0,58 & 0,5 \\
\hline 12. C83-87×Ocu. padre ........ & 0,01 & 0,01 & $-0,00$ & 0,02 & 0,06 & 1,00 & 0,31 \\
\hline 13. C41-51 XEdu. padre ......... & $-0,06$ & 0,06 & $-0,17$ & 0,05 & $-0,05$ & $-1,09$ & 0,278 \\
\hline 14. C52-61 XEdu. padre ........ & $-0,09$ & 0,05 & $-0,20$ & 0,01 & $-0,08$ & $-1,71$ & 0,088 \\
\hline 15. C62-74xEdu. padre ........ & $-0,08$ & 0,05 & $-0,18$ & 0,01 & $-0,10$ & $-1,76$ & 0,079 \\
\hline 16. C75-82XEdu. padre ......... & $-0,11$ & 0,05 & $-0,21$ & $-0,01$ & $-0,12$ & $-2,09$ & 0,036 \\
\hline 17. C83-87 XEdu. padre ......... & $-0,24$ & 0,06 & $-0,35$ & $-0,13$ & $-0,20$ & $-4,20$ & 0,000 \\
\hline & 1,02 & 0,11 & 0,80 & 1,24 & & 9,07 & 0,00 \\
\hline
\end{tabular}


es decir, de los cambios estructurales, deviene significativo, siguiendo la tendencia descendente, ahora negativa, descrita anteriormente. Una interpretación estricta atribuiría estas diferencias a los efectos del régimen político, en cuyo caso deberíamos concluir que la dictadura tuvo un impacto positivo sobre las oportunidades ocupacionales de los españoles. Si éste fuera el caso, y asumiendo que el nivel de dictadura hubiese permanecido igual durante todo el período, la pauta debería ser constante, no decreciente, como los datos parecen apuntar.

Una interpretación más razonable subrayaría la importancia de un proceso de modernización subyacente, abruptamente interrumpido por la guerra civil y la victoria del general Franco, suficientemente fuerte, sin embargo, para madurar lentamente durante la dictadura y explotar en el período democrático, cuando las trabas a la libre circulación de ideas y mercancías desaparecieron. Téngase en cuenta, de nuevo, que el efecto del «tiempo» (cambios estructurales) sobre las oportunidades ocupacionales de los entrevistados está reflejado en los datos en relación a sus orígenes sociales y logros educacionales. Aunque en términos absolutos los niveles ocupacionales correspondientes al primer empleo crecieron levemente durante el conjunto de los períodos analizados $^{48}$, lo hicieron en mucha menor medida, como veremos, que las oportunidades educativas de padres e hijos. Al controlar estos últimos efectos, la tendencia positiva desaparece para convertirse en negativa.

En suma, lo que los datos parecen mostrar es una importancia decreciente de la ocupación del padre en la determinación de la primera ocupación del hijo, junto con una tendencia opuesta hacia el reforzamiento de la relación entre los logros educacionales de padres e hijos y las posiciones alcanzadas por estos últimos en la jerarquía ocupacional. Como consecuencia de ambos procesos, el «tiempo» presenta un efecto negativo sobre las oportunidades ocupacionales de los entrevistados.

Sería un error atribuir estos procesos al efecto exclusivo de la industrialización. La industrialización alcanzó su punto álgido en España durante el período 1962-1974, cuando tanto el Producto Interior Bruto como el Indice de Producción Industrial crecieron a un ritmo anual sólo por debajo, entre los países desarrollados, de los alcanzados por Japón (Liberman, 1982). El período 1975-87 ha sido, en realidad, un período de desindustrialización, tal y como se refleja en el segundo de aquellos índices y en el porcentaje de población activa empleado en la industria (véase cuadro 1 en la sección 3.3).

Una explicación más plausible para la pauta descendente de la primera ocupación a lo largo del tiempo la asociaría a los cambios en el tamaño del mercado de trabajo que acompañan a los ciclos económicos. Una contracción en el mercado de trabajo, es decir, altas tasas de desempleo para el sector más joven de la población (estamos analizando la primera ocupación), rebajaría las expectativas ocupacionales de los entrevistados, haciéndoles aceptar posiciones más bajas (en términos de prestigio). Los datos secundarios a mi disposi-

t8 Véase tabla 5 en la sección 5.3.1 de este trabajo. 
ción tienden a confirmar esta hipótesis, al menos en lo que respecta a las diferencias entre períodos para el intervalo de tiempo abarcado por la dictadura, por un lado, y la democracia, por el otro. De hecho, la tasa de desempleo alcanzó su mínimo en el período $1962-74$ (Flager, Giner y Moreno, 1990), que presenta el coeficiente más bajo entre los tres periodos que definen la fase dictatorial. Si los datos estuvieran descompuestos por edades y sexo, esta interpretación sería más convincente. Afortunadamente, contamos con esa descomposición para el período 1977-1985. La tasa de desempleo fue más alta en 1977 que en 1985 para hombres de 16 a 19 años de edad, y más baja para los de 20 o más (Ministerio de Trabajo y Seguridad Social, 1986). Puesto que la última cohorte (1983-87) infrarrepresenta, con toda probabilidad, el subgrupo de 16 a 19 años y sobrerrepresenta el de 20 y más, el coeficiente para este período debería ser, y es, menor que el correspondiente a 1975-8249. Desde luego, la ausencia de diferencias significativas entre períodos ${ }^{50}$ y de información sobre las características de los parados, ya sea que busquen su primer empleo (el subconjunto que más nos interesal o que hayan trabajado antes, aportan dudas sobre la validez de esta interpretación. En cualquier caso, una explicación basada en las diferencias entre regímenes políticos, ya sea subrayando sus características políticas o económicas, pasaría por alto el proceso continuo y lento que los datos parecen mostrar ${ }^{51}$.

Cuando analizamos los efectos de cada período sobre las oportunidades educativas de los entrevistados (filas 3 a 7 en la tabla 3B) encontramos una pauta opuesta, tal y como sucedió al analizar el modelo completo. Los datos muestran un creciente efecto positivo del «tiempo» sobre los logros educacionales de los entrevistados, netos de otras influencias en el modelo. La única excepción afecta al coeficiente correspondiente al período 1962-74, algo más pequeño que el correspondiente a 1951-61, sin que esa diferencia alcance la

49 Debido a que el universo se restringió en la muestra a los mayores de 18 años, la cohorte 1983-87 no incluye a los entrevistados que ingresaron en el mercado de trabajo a edades más tempranas (con 17 o menos años en 1987, con 13 o menos en 1983). Esto tendería a infrarrepresentar aquellas ocupaciones que no requieren credenciales educativas medias y superiores y a sobrerrepresentar las ocupaciones de estatus más altos. Los resultados extremadamente negativos obtenidos para esta cohorte podrían deberse, precisamente, a este inevitable problema de selección.

50 Sólo las cohortes 1941-51 y 1983-87 son significativamente diferentes entre sí (al nivel 0,05 ) respecto a sus efectos directos sobre la ocupación del hijo, puesto que sus intervalos de confianza no se solapan. La existencia de «heteroesquedasticidad» en los datos, detectada mediante el test de Breusch-Pagan y las gráficas de residuos estandarizados para cada valor de las variables independientes, podría explicar esta ausencia de otras diferencias significativas (puesto que el término de error tiende a aumentar según avanzamos hacia valores más altos en esas variables). De haber corregido este problema de manera más satisfactoria, los datos hubieran mostrado, seguramente, mayores diferencias significativas.

${ }^{51}$ Una última explicación es todavía posible. La creciente incorporación de las mujeres al mercado de trabajo, especialmente en el período democrático, y su presión sobre los puestos de trabajo anteriormente reservados a los hombres podría haber provocado este descenso medio en los estatus ocupacionales de los hombres. En este momento no dispongo de suficiente información para aceptar o refutar esta hipótesis. 
significación ${ }^{52}$. Todos los coeficientes son significativamente diferentes del coeficiente implícito para el período anterior a 1941. Además, los correspondientes a 1975-82 y 1983-87 son significativamente más altos que el del período 1941-51. El resto de diferencias entre períodos no son significativas al nivel 0,05 . En suma, los procesos de modernización habidos en el país han tenido un efecto positivo sobre las oportunidades educativas de los españoles, lo que confirmaría nuestra noción sobre las crecientes necesidades educativas de una economía moderna, cada vez más basada en los servicios.

Nos centraremos ahora en los efectos interactivos de las cohortes y la educación de los entrevistados sobre la primera ocupación. Las últimas cinco filas de la tabla $3 \mathrm{~A}$ (exceptuando la correspondiente a la constante) estiman los cambios en el efecto de la educación en cada cohorte respecto al período anterior a 1941. Sólo dos son significativos: los correspondientes a los dos períodos que conforman la fase democrática (1975-87). Allí, el efecto de los logros educacionales alcanzados por los entrevistados sobre sus oportunidades ocupacionales iniciales es casi el doble que antes de $1941^{53}$. Esta diferencia es el resultado final de una tendencia positiva más lenta y progresiva que empieza en los años cincuenta y termina en nuestros días. Se perciben dos interrupciones menores en ella: en los períodos 1962-74 y 1983-87.

Empezando por la primera, parecería como si el período expansivo de los sesenta y primera mitad de los setenta hubiera debilitado, relativamente, los lazos existentes entre los logros educativos y ocupacionales de los entrevistados, probablemente debido a la demanda creciente de mano de obra en el sector industrial y el sector servicios ${ }^{54}$. Es éste el período de las grandes migraciones interiores del campo a la ciudad, y de las migraciones exteriores hacia los países más desarrollados de Europa occidental ${ }^{55}$. Si nuestra interpretación es correcta, un fuerte proceso de industrialización debilitaría los lazos entre la educación y la ocupación, exactamente la tesis contraria a la mantenida por Featherman y Hauser en Opportunity and Cbange (1978).

La segunda interrupción se produce en el período 1983-87. Recuérdese que esta cohorte sobrerrepresenta a los entrevistados que ingresaron en el mercado de trabajo a edades más tardias ${ }^{56} \mathrm{y}$, por lo tanto, a las ocupaciones que requieren credenciales educativas superiores para su ejercicio. Los resul-

52 Cuando las cohortes de entrada en el mercado de trabajo se sustituyen por cohortes definidas por las fechas en que los entrevistados cumplieron los 16 años, el orden ascendente de todas las cohortes sucesivas se confirma, sin que los coeficientes difieran excesivamente de los obtenidos con anterioridad.

s3 El coeficiente para el período anterior a 1941 aparece bajo la rúbrica «educación del hijo». El efecto de la educación del entrevistado en 1975-82 viene dado por la suma de los coeficientes correspondientes a la educación del hijo y a la interacción entre esta variable y la cohorte 1975-82.

${ }^{54}$ Que, por término medio, alcanzan puntuaciones más altas en la escala de Treiman que las ocupaciones agrícolas.

${ }^{55}$ Más de 4 millones de españoles cambiaron de provincia de residencia en ese tiempo. Se estima que cerca de 3 millones abandonaron nuestro país (Díz Nicolás, 1990; Harrison, 1985).

56 Véase nota 49. 
tados apuntan a una creciente devaluación de esas credenciales en el mercado de trabajo, probablemente debido a la masificación de la enseñanza superior, consecuencia de una planificación en poco acorde con la configuración real y las necesidades de ese mercado.

\subsection{PROCESOS DE MOVILIDAd EN EL TIEMPO}

Las pautas descritas hasta el momento expresan nuestra estimación de los efectos directos del cambio social sobre las oportunidades educativas y ocupacionales de los entrevistados. Sin embargo, el efecto del cambio social no se agota aquí. También ha modificado los procesos de transmisión intergeneracional de estatus de padres a hijos. Puesto que los efectos cruzados de la ocupación del padre sobre la educación del hijo y de la educación del padre sobre la primera ocupación del hijo son pequeños, sustantivamente menos importantes y casi constantes para la totalidad del período analizado, nos centraremos en esta parte del análisis en los cambios históricos en los procesos intergeneracionales de movilidad educacional y ocupacional. Para ello, trabajaremos con los términos de interacción incluidos en las tablas $3 \mathrm{~A}$ y $3 \mathrm{~B}$ y con los resultados que se presentan en las tablas 5, 5A, 6 y $6 \mathrm{~A}$ (véase más adelante), que descomponen esa movilidad en sus componentes relevantes. Empezaremos nuestro análisis con la movilidad ocupacional.

\subsubsection{Procesos de movilidad: de la ocupación del padre a la primera ocupación del bijo}

Con el fin de clarificar el análisis, empezaremos por fechar las ocupaciones de padres e hijos y por analizar las distribuciones de edad de unos y otros en cada cohorte. La tabla 4 muestra esta información.

Impacta a primera vista que la fecha media de las ocupaciones de los padres $^{57}$ sea subsecuente, para las primeras cohortes, a la fecha media en que los hijos ingresaron en el mercado de trabajo. Esto refleja una tendencia histórica hacia una incorporación más tardía al mercado de trabajo, claramente como consecuencia de los avances educacionales en el país ${ }^{58}$. La media de edad al ingresar en el mercado de trabajo aumenta con el tiempo, lo que apoya nuestra explicación.

Deberíamos concluir, por lo tanto, que, para las tres últimas cohortes, un modelo como el aquí propuesto, que explica los logros ocupacionales de los hijos por los alcanzados por sus padres, es lógicamente incongruente para muchos entrevistados. Para que el modelo fuera razonable deberíamos asumir 16 años.

57 Que corresponde exactamente a la fecha media en que los entrevistados cumplieron

${ }^{58} \mathrm{Y}$ para los dos últimos períodos, a las crecientes tasas de desempleo juvenil 


\section{TABLA 4}

\section{Indicadores temporales para los datos ocupacionales}

\begin{tabular}{|c|c|c|c|c|c|c|c|c|c|c|c|}
\hline \multirow{3}{*}{$\begin{array}{c}\text { Entrada en mercado } \\
\text { trabajo }\end{array}$} & \multirow[b]{3}{*}{$N$} & \multirow[b]{3}{*}{$\%$} & \multicolumn{6}{|c|}{ Hijos } & \multicolumn{3}{|c|}{ Padres } \\
\hline & & & \multicolumn{2}{|c|}{ Ocupación en } & \multicolumn{2}{|c|}{ A la edad } & \multicolumn{2}{|c|}{ Nacimiento } & \multirow{2}{*}{$\frac{\text { Ocup. en }}{\bar{X}}$} & \multirow{2}{*}{$\frac{A \text { edad }}{*}$} & \multirow{2}{*}{$\frac{\text { Nacim. }}{*}$} \\
\hline & & & $\bar{X}$ & $\sigma$ & $\bar{X}$ & $\sigma$ & $\bar{X}$ & $\sigma$ & & & \\
\hline 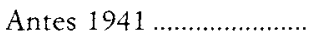 & 707 & 16,3 & 1931,5 & 7,11 & 13,3 & 3,91 & 1918,1 & 7,1 & 1934,1 & $44-56$ & $1878-90$ \\
\hline 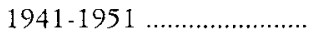 & 699 & 16,1 & 1946,2 & 3,13 & 15,1 & 4,34 & 1931,2 & 5,1 & 1947,2 & $45-53$ & $1894-02$ \\
\hline 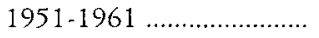 & 666 & 15,3 & 1956,6 & 2,81 & 16,5 & 4,52 & 1940,1 & 5,1 & 1956,1 & $45-53$ & $1903-11$ \\
\hline $1962-1974 \ldots \ldots \ldots \ldots \ldots \ldots \ldots \ldots \ldots \ldots \ldots$ & 1.112 & 25,6 & 1968,1 & 3,71 & 17,1 & 4,47 & 1951,0 & 5,7 & 1967,0 & $43-50$ & $1917-24$ \\
\hline $1975-1982 \ldots \ldots \ldots \ldots \ldots \ldots \ldots$ & 772 & 17,8 & 1978,3 & 2,20 & 18,2 & 3,98 & 1960,2 & 4,3 & 1976,2 & $43-47$ & $1929-33$ \\
\hline \multirow[t]{2}{*}{$1983-1987 \ldots \ldots \ldots \ldots \ldots \ldots \ldots$} & 386 & 8,9 & 1984,6 & 1,12 & 20,5 & 3,85 & 1964,0 & 3,9 & 1980,0 & $43-47$ & $1933-37$ \\
\hline & 4.342 & 100 & 1960,1 & 17,62 & 16,6 & 4,68 & 1943,6 & 16,2 & 1959,2 & & \\
\hline
\end{tabular}

* Basado en la media de edad del hijo en la fecha de realización de la encuesta, en la fecha media de la ocupación del padre y en la información que se presenta en el siguiente cuadro:

Edad media del padre al nacimiento de su primer y último bijos

\begin{tabular}{|c|c|c|c|c|}
\hline & 1900 & 1950 & $1970-75$ & $1981-85$ \\
\hline (1) & 27,7 & 29,3 & 26,8 & 26,5 \\
\hline Ultimo hijo & 40,4 & 36,8 & 34,3 & 31,1 \\
\hline
\end{tabular}

Fuente: Lluís Flaquer, «La familia española: cambio y perspectivas», en Salvador Giner (ed.), Sociedad y política, Espasa-Calpe, 1990. 
que la ocupación del padre no cambió demasiado durante el lapso de tiempo que va desde la fecha correspondiente a la primera ocupación del entrevistado y la correspondiente a la ocupación del padre. Creo que esta asunción no está muy lejos de la realidad, puesto que la ocupación está medida en términos de prestigio social ${ }^{59}$. La diferencia entre ambas fechas, ya sea positiva o negativa, es lo suficientemente pequeña como para permitirnos interpretar ambos momentos como simultáneos en el tiempo. De estar en lo cierto, la magnitud de movilidad estructural debería ser pequeña, pues reflejaría sólo parcialmente las diferencias en las estructuras ocupacionales de padres e hijos. Ateniéndonos a este discurso, la movilidad estructural mediría las diferencias en las estructuras ocupacionales de los segmentos joven y adulto de una misma estructura ocupacional (véanse diferencias en la edad media de padres e hijos en la tabla 4).

Presentaremos más adelante los resultados correspondientes a la descomposición de la movilidad ocupacional en sus componentes estructural y de intercambio ${ }^{60}$. Pero, antes de concentrar nuestros esfuerzos en esos temas, permítasenos retroceder a nuestro modelo de «logro de estatus» y comentar los cambios en los efectos de la ocupación del padre sobre la primera ocupación del hijo. Las inconsistencias que acabamos de identificar no anulan la validez de la relación causal entre la ocupación del padre y la ocupación del hijo, al menos en lo que respecta a las tres últimas cohortes. En lo que sigue, seguiremos considerando a la ocupación del padre como un índice de las oportunidades iniciales provistas a sus hijos ${ }^{61}$.

Las filas 8 a 12 en la tabla 3 A muestran el efecto compuesto de la ocupación del padre y la cohorte sobre las oportunidades ocupacionales del entrevistado en el momento de incorporarse al mercado de trabajo. De acuerdo con los coeficientes no estandarizados, el efecto de la ocupación del padre ha declinado con el tiempo. Este proceso decreciente, que empieza en los cuarenta, cuando la ocupación del padre aún mantiene un efecto positivo sobre la ocupación del hijo, alcanza la significación sólo en los años sesenta y setenta, y se invierte en el período 1983-87.

Aquella pauta general decreciente confirmaría una de nuestras hipótesis más importantes, aunque reformulada en términos de modernización en vez de industrialización. A medida que el país fue modernizándose, la relación entre la ocupación del padre y la primera ocupación del hijo fue debilitándose, haciéndose menos determinista. Veremos más tarde que los efectos indirectos a través de la educación del hijo permanecieron prácticamente constantes, con un efecto menor de los orígenes ocupacionales sobre la educación del hijo y un efecto mayor de la educación del padre sobre la educación del hijo.

Cuándo alcanzan los coeficientes la significación ${ }^{62}$ puede darnos una pista

5) Por lo tanto, más rígida o menos proclive a un cambio brusco en el tiempo.

(11) Véase sección 2.2 de este trabajo, para una definición y discusión de estos conceptos.

n Pero reconociendo que estamos trabajando con una magnitud desconocida (estimo que pequeña, dadas las consideraciones precedentes) de error sistemático.

6.2 Esto es, cuándo se diferencian significativamente del período anterior a 1941. 
sobre el ritmo de ese proceso decreciente. Ha sido más rápido (significativo a partir de 1962) que el declive neto en las oportunidades ocupacionales iniciales de los entrevistados (a partir de 1975), que el proceso de reforzamiento de los lazos entre la educación y la primera ocupación de los hijos (1975) y, como veremos más adelante, más rápido que el declive en la importancia de la educación del padre en la determinación de los logros educacionales de sus hijos (1975).

Esto apoyaría la interpretación de que 1962-1974 fue un período muy importante en la historia de España. Ese período, que enmarca una sociedad con un nivel educativo todavía bajo, no muy diferente al de sus padres, canalizó la ruptura con el pasado a través, principalmente, del cambio ocupacional ${ }^{63}$. Esto no significa que los hijos no experimentaran mejoras educativas respecto a sus padres y, a través de ellas, sobre sus logros ocupacionales. Significa que los cambios en la movilidad ocupacional se adelantaron a los cambios en la movilidad educativa y que, en ese período, el cambio ocupacional intergeneracional no fue debido tanto a las mejoras educativas (recuérdese la atenuación, para este período, en la pauta ascendente del efecto de la educación sobre la primera ocupación de los hijos) como a la debilitación de los efectos de la ocupación del padre.

La inflexión para la cohorte 1983-87 es analíticamente (no estadísticamente) muy significativa, a la luz de los resultados obtenidos anteriormente para esta misma cohorte. Vendría a confirmar el fenómeno de sobrerrepresentación de entrevistados con credenciales educativas superiores al que aludíamos antes. $\mathrm{La}$ atenuación del efecto de los propios logros educacionales sobre las posibilidades de alcanzar estatus ocupacionales superiores, ya comentada, se explicaría por, o complementaría con, el mayor peso relativo de la ocupación del padre en la determinación de esas posibilidades ocupacionales. Encontrándonos en el segmento más alto de la jerarquía educacional, es lógico que las mejoras educativas tengan un impacto menor en este segmento que en el conjunto de los entrevistados. A credenciales educativas similares, es la ocupación del padre la que mejor explica las diferencias ocupacionales de los hijos al ingresar en el mercado de trabajo. Por lo tanto, más que una inflexión en el efecto de la ocupación del padre sobre la primera ocupación del hijo, nos encontraríamos en esta cohorte con un fenómeno de sobrerrepresentación de los segmentos superiores de las jerarquías educativa y ocupacional. Nótese, sin embargo, que la inflexión en la importancia decreciente de la ocupación del padre es superior, en términos relativos, a la atenuación en la importancia creciente de la propia educación. Si consideramos también los fuertes efectos negativos (netos) del período sobre las oportunidades ocupacionales de los entrevistados, podemos avanzar ya una hipótesis preliminar que debería contrastarse mejor en el futuro ${ }^{64}$, a saber, que la progresiva universalización de la

${ }_{63}$ En verdad, ese cambio pudo entrañar tanto pérdidas como ganancias, aunque, como veremos más adelante cuando analicemos los componentes de la movilidad ocupacional, la segunda interpretación es más plausible.

ot Analizando este segmento superior en el resto de las cohortes. 
enseñanza superior tuvo en España un efecto inicial (hasta principios de los ochenta) positivo muy importante sobre las oportunidades ocupacionales de los entrevistados al ingresar en el mercado de trabajo. Sin embargo, con la progresiva incorporación de los estratos medio-bajos a la enseñanza superior, las instituciones educativas se masificaron y sus credenciales se devaluaron en el mercado de trabajo. El papel regulador de este mercado habría provocado un declive neto en las oportunidades ocupacionales de este segmento de la población, fundamentalmente en los individuos de procedencia social más baja, dado el reforzamiento de los componentes adscriptivos en la determinación de esas oportunidades.

Pero centrémonos ahora en los procesos de transmisión de estatus de padres a hijos a lo largo del tiempo. La tabla 5 presenta la descomposición de la movilidad intergeneracional en sus componentes relevantes, por cohortes, junto con las medias, medianas, desviaciones típicas y coeficientes de variación de las variables ocupación del padre y primera ocupación del hijo y sus correlaciones. Esta descomposición está basada en el método propuesto por McClendon en 1977.

\section{TABLA 5}

Componentes de la movilidad ocupacional intergeneracional

\begin{tabular}{|c|c|c|c|c|c|c|}
\hline & $\begin{array}{c}\text { Antes } \\
1941\end{array}$ & $1941-51$ & $1952-61$ & $1962-74$ & $1975-82$ & $1983-87$ \\
\hline (................... & 32,983 & 34,494 & 35,521 & 35,379 & 35,642 & 36,098 \\
\hline . & 34,539 & 34,023 & 35,248 & 35,830 & 36,010 & 37,992 \\
\hline ( & 0,443 & 0,430 & 0,346 & 0,397 & 0,339 & 0,417 \\
\hline 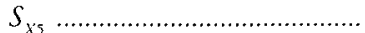 & 9,704 & 9,961 & 10,399 & 11,183 & 12,197 & 13,363 \\
\hline$s_{x 3} \ldots \ldots$ & 10,612 & 10,509 & 10,783 & 11,665 & 10,904 & 11,563 \\
\hline $\mathrm{CV}\left(X_{5}\right)$ & 0,29 & 0,29 & 0,29 & 0,31 & 0,32 & 0,37 \\
\hline $\mathrm{CV}\left(X_{3}\right)$ & 0,31 & 0,31 & 0,31 & 0,33 & 0,31 & 0,30 \\
\hline Mediana $\left(X_{3}\right) \ldots \ldots \ldots \ldots \ldots \ldots \ldots \ldots \ldots \ldots \ldots \ldots \ldots \ldots \ldots$ & 35 & 34 & 36 & 34 & 34 & 40 \\
\hline \multicolumn{7}{|l|}{ Movilidad: } \\
\hline Absoluta & 10,86 & 10,95 & 12,12 & 12,56 & 13,33 & 13,36 \\
\hline Intercambio ............. & 10,24 & 10,64 & 11,89 & 12,28 & 14,02 & 14,43 \\
\hline 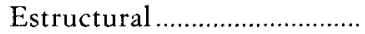 & 1,80 & 0,72 & 0,47 & 0,66 & 1,35 & 2,27 \\
\hline 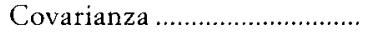 & 4,91 & 3,11 & 2,61 & 3,25 & $-7,71$ & $-16,26$ \\
\hline
\end{tabular}

$X_{5}=$ Ocupación del hijo.

$X_{3}=$ Ocupación del padre.

En su artículo, McClendon subraya la necesidad de definir la movilidad vertical en función de las posiciones relativas de los individuos en sus respectivas distribuciones. McClendon define primeramente la movilidad estructural, la de intercambio y la movilidad absoluta a nivel individual, para después 
proporcionar los medios para estimar esos componentes al nivel agregado. Al nivel individual, los diferentes componentes de la movilidad se definen por las siguientes fórmulas ${ }^{65}$ :

Estructural

$X_{5}{ }^{\prime}-X_{3}=\left(s_{15}-s_{X 3}\right) Z_{X 3}+\left(X_{5}-X_{3}\right)$
Intercambio

$$
X_{5}-X_{5}{ }^{\prime}=s_{X 5}\left(Z_{X 5}-Z_{X 3}\right)
$$

Absoluta

$$
\left(X_{5}-X_{5}^{\prime}\right)+\left(X_{5}^{\prime}-X_{3}\right)=X_{5}-X_{3}
$$

donde $X_{5}$ y $X_{3}$ representan las posiciones (puntuaciones) de padres e hijos en sus respectivas distribuciones ocupacionales; $Z_{X 5}$ y $Z_{X 3}$, esas mismas posiciones definidas ahora en términos de desviaciones típicas respecto a las medias $\left(X_{5}\right.$ y $X_{3}$ ) de las distribuciones; $s_{X 5}$ y $s_{X 3}$, las desviaciones típicas de las dos variables; y $X_{5}{ }^{4}\left[=s_{X 5}\left(Z_{X 5}-Z_{X 3}\right)\right]$, el estatus de un hijo con nula movilidad de intercambio. Tal y como McClendon señala, la movilidad de intercambio de un hijo es en parte función de la magnitud de desigualdad (desviación típica) existente en la estructura ocupacional a la que pertenece. Debido a la regresión hacia la media, hijos con puntuaciones por encima de la media en la escala de Treiman tenderán a experimentar movilidad descendente, e hijos con puntuaciones por debajo de ella tenderán a experimentar movilidad ascendente, la magnitud de esta tendencia variando inversamente con la magnitud de la correlación $(r)$ entre la ocupación del padre y la primera ocupación del hijo.

Para el nivel agregado, los distintos componentes de la movilidad se definen por las raíces cuadradas de las siguientes expresiones algebraicas:

$$
\begin{array}{ll}
\text { Estructural } & \Sigma\left(X_{5}{ }^{\prime}-X_{3}\right)^{2} / N=\left(X_{5}-X_{3}\right)^{2}+\left(s_{X 5}-s_{X 3}\right)^{2} \\
\text { Intercambio } & \Sigma\left(X_{5}-X_{5}{ }^{\prime}\right)^{2} / N=2 s^{2}{ }_{X 5}(1-r) \\
\text { Absoluta } & \Sigma\left(X_{5}-X_{3}\right)^{2} / N=\left(X_{5}-X_{3}\right)^{2}+s_{X 5}+s_{X 3}-2 s_{X 5} s_{X 3} r
\end{array}
$$

Por otra parte, McClendon define la covarianza entre la movilidad estructural y la de intercambio como un indicador del cambio en la desigualdad de las estructuras ocupacionales de padres e hijos. La covarianza $\left[s_{\left.\left(X 5-X 5^{\prime}\right) X X^{\prime}-X 3\right)}=s_{X 5}\left(s_{X 3}-s_{X 5}\right)(1-r)\right]$ es positiva cuando la desigualdad es mayor en la primera, negativa en caso contrario.

Ahora estamos en condiciones de comentar los resultados de la tabla 5 . Ha habido un incremento en el promedio de los estatus ocupacionales de los entrevistados al ingresar en el mercado de trabajo. Solamente en 1962-74 la media de las puntuaciones de los hijos en la escala de Treiman fue más baja que en el período precedente, sin que esa diferencia alcance la significación. La distribución correspondiente a los padres sigue una pauta similar. Excepto para los períodos 1941-51 y 1952-61, la media de las puntuaciones de los padres es siempre más alta que la de sus hijos. Acompañando a esta tendencia, ha habido un aumento en la desigualdad ocupacional de los hijos, tal y como

(15 Estas fórmulas se presentan aquí sin prueba. Para una explicación detallada, véase el artículo original de $\mathrm{McClendon.}$ 
reflejan los cambios en los correspondientes coeficientes de variación ${ }^{66}$, y apenas ha habido cambio alguno en las distribuciones de los padres. La covarianza entre la movilidad estructural y la de intercambio es negativa para los dos períodos correspondientes a la fase democrática, indicando que sólo en ese momento la desigualdad en la estructura ocupacional de los hijos superó a la observada en la distribución de los padres.

Tal y como se predijo al comentar las fechas correspondientes a las ocupaciones de padres e hijos, la magnitud de movilidad estructural es muy pequeña, alrededor de un 19 por 100 de la desviación típica de la ocupación de los hijos, consistentemente menor que la magnitud de movilidad de intercambio en cada cohorte. La cohorte $1952-61$ es la que presenta menor movilidad estructural, siendo esta cohorte la que menores diferencias presentaba entre las fechas correspondientes a las ocupaciones de padres e hijos (medias casi simultáneas). Debido a la proximidad de esas fechas para todas las cohortes, la movilidad estructural es un pobre indicador de los efectos de los cambios estructurales sobre las oportunidades de movilidad de los entrevistados. Sólo corrige la heterogeneidad observada en los marginales de la tabla de movilidad intergeneracional, que en gran parte refleja las diferencias de edad entre padres e hijos.

Tanto la movilidad de intercambio como la movilidad absoluta aumentan uniformemente con el tiempo. La mayor magnitud de movilidad absoluta en los períodos 1974-82 y 1983-87 es explicable tanto por la mayor magnitud de movilidad de intercambio como por la covarianza negativa entre la movilidad estructural y la de intercambio (debido al aumento en la desigualdad), mientras que para el resto de las cohortes solamente refleja el aumento en la movilidad de intercambio.

Centrándonos en la movilidad de intercambio, uno se siente tentado de explicarla como consecuencia del incremento en la desigualdad y/o por el debilitamiento de la correlación entre la ocupación de padres e hijos. Sin embargo, los cambios en esa correlación, por ejemplo su incremento en 196274 respecto al período precedente, pueden ser debidos meramente a la asociación entre la ocupación del padre y otros factores no incluidos en el análisis, que estarían correlacionados tanto con la ocupación del padre como con la primera ocupación del hijo. Ya vimos antes cómo el efecto directo de la ocupación del padre sobre la primera ocupación del hijo declinó uniformemente a lo largo de las cohortes, una vez controlados los efectos de las otras variables independientes. Cuando sustituimos las correlaciones de orden cero entre la ocupación del padre y la primera ocupación del hijo por sus correlaciones parciales ${ }^{67}$, obtenemos una visión más clara de las pautas en la movili-

or El coeficiente de variación (la desviación típica dividida por la media) corrige el impacto de las diferencias entre las medias de las distribuciones sobre la desviación típica, de manera que es un mejor índice de desigualdad que esta última (Jencks, 1972).

67 Una medida de la asociación entre esas dos variables, una vez que se eliminan los efectos (o asociaciones) de la educación del padre y la educación del hijo sobre aquella asociación. 
dad de intercambio. En la tabla 5A reproducimos los nuevos índices de movilidad de intercambio y las correlaciones parciales, por cohortes.

TABLA 5A

Movilidad ocupacional de intercambio, una vez «controlados» los efectos de la educación del padre y del bijo

\begin{tabular}{|c|c|c|c|c|c|c|}
\hline & $\begin{array}{c}\text { Antes } \\
1941\end{array}$ & $1941-51$ & $1952-61$ & $1962-74$ & 1975.82 & $1983-87$ \\
\hline .................... & 0,352 & 0,331 & 0,261 & 0,225 & 0,187 & 0,273 \\
\hline Mov. de intercambio ............ & 11,05 & 11,52 & 12,64 & 13,92 & 15,56 & 16,11 \\
\hline
\end{tabular}

$X_{5}=$ Ocupación hijo $\quad X_{3}=$ Ocupación padre $\quad X_{2}=$ Educación padre $\quad X_{4}=$ Educación hijo

Los índices de movilidad «pura» son consistentemente más altos que en la tabla 5 , reflejando el hecho de que, una vez que controlemos los efectos de la educación del padre y del entrevistado sobre la movilidad ocupacional, la liberaremos de parte de sus ataduras. Los coeficientes de correlación parcial decrecen con el tiempo (excepción: la última cohorte). Esta pauta decreciente se ha visto acompañada de un incremento en la magnitud de la desigualdad. Ambas tendencias produjeron un aumento continuo en el volumen de movilidad ocupacional (liberada de componentes estructurales) a medida que el país se fue modernizando. Este proceso es lento hasta 1952 y algo más rápido a partir de entonces, con el incremento relativo más alto en el período 1975:82 y una pequeña inflexión en la última cohorte $^{68}$. Dada esta tendencia casi uniforme, deberíamos concluir que ningún factor estructural (por ejemplo, la industrialización, los ciclos económicos, los regímenes políticos) ha tenido, por sí solo, un efecto especial sobre las pautas de movilidad ocupacional de los varones en España. Más probablemente, ha sido un compendio de todos ellos, lo que vagamente hemos definido como «modernización», lo que provocó esos cambios.

Por último, nótese que sólo en 1962-74 y 1975-82 la mediana de la distribución de la ocupación del padre está por debajo de su media, indicando que más del 50 por 100 de los padres se encontraban por debajo del valor medio de esa distribución. Puesto que los hijos con padres por encima de la media tienden a experimentar movilidad descendente, mientras que los hijos con padres situados por debajo de esa media tienden a experimentarla ascendente, podemos concluir que, en estos dos períodos, la movilidad ascendente superó

${ }^{6} 8$ Que concuerda con la inflexión en la tendencia decreciente de los efectos de la ocupación del padre, observada al analizar los coeficientes de la regresión aplicada al modelo de cohortes. 
a la movilidad descendente (en volumen) ${ }^{69}$. El mayor volumen de movilidad descendente para el período 1983-87 vendría a corroborar las características particulares de esta cohorte, tal y como se presentaron anteriormente.

\subsubsection{Procesos de movilidad: de la educación del padre a la educación del bijo}

Volvemos ahora a los resultados mostrados en la tabla 3B. Como en el caso de la ocupación, también ha habido un declive continuado en los efectos directos de la educación del padre sobre la educación del hijo, con una atenuación suave en el período 1962-74. Los coeficientes correspondientes a los términos de interacción entre la «cohorte» y la «educación del padre» (variables 13 a 17 en la tabla 3B) son todos negativos, reflejando esa tendencia. Sólo en 1975 este proceso deviene significativo con respecto al período anterior a 1941. Pero no se trata de ninguna ruptura con el pasado. Es solamente la parte visible de un proceso que se inició veinticinco años antes. Un proceso caracterizado por un incremento en los niveles educativos de los entrevistados con respecto al de sus padres.

TABLA 6

Componentes de la movilidad educacional

\begin{tabular}{|c|c|c|c|c|c|c|}
\hline & $\begin{array}{c}\text { Antes } \\
1941\end{array}$ & $1941-51$ & $1952-61$ & $1962-74$ & $1975-82$ & $1983-87$ \\
\hline$\ddot{X}_{4}$ & 2,528 & 2,309 & 3,017 & 3,356 & 3,636 & 3,684 \\
\hline$X_{2}$. & 2,093 & 2,810 & 2,380 & 2,542 & 2,619 & 2,816 \\
\hline ................... & 0,561 & 0,558 & 0,479 & 0,539 & 0,466 & 0,422 \\
\hline$\ldots$ & 0,857 & 0,804 & 0,870 & 1,005 & 1,008 & 1,006 \\
\hline 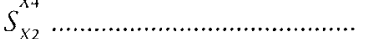 & 0,814 & 0,842 & 0,887 & 0,971 & 0,928 & 1,105 \\
\hline $\mathrm{CV}\left(X_{4}\right) \ldots \ldots \ldots \ldots \ldots \ldots \ldots \ldots$ & 0,34 & 0,35 & 0,29 & 0,30 & 0,28 & 0,27 \\
\hline $\mathrm{CV}\left(X_{2}\right)$ & 0,39 & 0,30 & 0,37 & 0,38 & 0,35 & 0,39 \\
\hline Mediana $\left(X_{2}\right) \ldots \ldots \ldots \ldots \ldots \ldots \ldots \ldots$ & 2 & 2 & 2 & 2 & 3 & 3 \\
\hline \multicolumn{7}{|l|}{ Movilidad: } \\
\hline Absoluta ... & 0,89 & 0,92 & 1,10 & 1,25 & 1,43 & 1,43 \\
\hline Intercambio & 0,80 & 0,75 & 0,91 & 0,96 & 1,04 & 1,08 \\
\hline Estructural ............................ & 0,44 & 0,50 & 0,64 & 0,81 & 1,02 & 0,87 \\
\hline 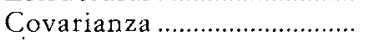 & $-0,02$ & 0,01 & 0,01 & $-0,02$ & $-0,04$ & 0,06 \\
\hline
\end{tabular}

$X_{t}=$ Educación del hijo. $\quad X_{2}=$ Educación del padre.

(3) Puesto que el sumatorio de las distancias entre padres e hijos debe ser cero, el mayor volumen de movilidad ascendente debería ser compensado con una movilidad descendente de mayor distancia o longitud. 
Tal y como se refleja en la tabla 6 , la diferencia entre los promedios educativos de padres e hijos ha aumentado de cohorte en cohorte, excepto en la última de ellas ${ }^{70}$. Este promedio, que para los hijos está en torno a los seis años de escuela en 1941-51, crece hasta los once-doce años en 1983-87 ${ }^{71}$. La pauta decreciente en los coeficientes de variación indica que las ganancias educativas de los entrevistados fueron acompañadas de un declive a lo largo del tiempo en la desigualdad educacional.

A diferencia del cambio ocupacional, que en una economía de mercado es menos sensible a la directa intervención de un único agente causal, las pautas educativas reflejan en mayor proporción los efectos directos de las políticas gubernamentales (por ejemplo, la legislación sobre escolarización obligatoria) ${ }^{72}$. Estos efectos, yo argumentaría, deberían afectar principalmente al componente estructural de una tabla de movilidad, al modificar tanto la media como la desviación típica de las distribuciones de orígenes y destinos. La movilidad estructural aumenta casi uniformemente a lo largo del tiempo, así como su contribución a la magnitud de movilidad absoluta. En consecuencia, las tres reformas educativas más importantes habidas en la segunda mitad del siglo $(1953,1970$ y 1985) no parece que hayan tenido un efecto inmediato en esta tendencia. Si lo tuvieron, lo hicieron de forma mucho más gradual a lo que cabría esperar a partir de los objetivos explícitos de sus legisladores.

Mientras que la magnitud de movilidad estructural representa sólo la mitad de la movilidad de intercambio experimentada antes de 1941, alcanza valores cercanos a ésta en 1975-82, aun cuando la tendencia en la movilidad de intercambio sea igualmente ascendente. Esto es, el ritmo de incremento de la movilidad estructural ha sido mucho más alto que el de la movilidad de intercambio. Este hecho no se ve afectado por posibles omisiones de otras causas relevantes en el cálculo de la movilidad de intercambio. La tabla 6A muestra los resultados de la movilidad de intercambio, una vez sustituida la correlación de orden cero entre la educación de padres e hijos por su correlación parcial, controlando así la asociación entre la ocupación del padre y la educación del hijo.

A diferencia de la movilidad ocupacional, la movilidad educativa de intercambio no varía en proporciones importantes al sustituir las correlaciones de orden cero por sus correspondientes correlaciones parciales, lo que refleja el pequeño impacto que la ocupación del padre tiene sobre los logros educacionales de su hijo. Sin embargo, la sustitución ayuda a identificar los factores que están detrás de la tendencia creciente hacia una mayor movilidad de intercambio. Dado el pequeño incremento en la desviación típica de las distribuciones correspondientes a los hijos, la pauta ascendente de la movilidad de

${ }^{70}$ Aun cuando también los padres experimentaron ligeras mejorías en sus niveles educativos.

${ }^{71}$ Véase sección 3.2 en este artículo para consultar las correspondencias entre los valores operacionales de las variables de educación y los años de escuela.

72 Aunque retardadas en el tiempo. La implementación de las políticas gubernamentales se realiza a menudo de forma mucho más gradual. 


\section{TABLA 6A}

\section{Movilidad educacional de intercambio, una vez controlado el efecto de la ocupación del padre}

\begin{tabular}{|c|c|c|c|c|c|c|}
\hline & $\begin{array}{c}\text { Antes } \\
1941\end{array}$ & $1941-51$ & $1952-61$ & $1962-74$ & $1975-82$ & $1983-87$ \\
\hline$r_{X+X 2 \times 3} \ldots \ldots \ldots \ldots$ & 0,513 & 0,490 & 0,435 & 0,424 & 0,378 & 0,312 \\
\hline Mov. de intercambio ............. & 0,85 & 0,81 & 0,92 & 1,08 & 1,12 & 1,18 \\
\hline
\end{tabular}

intercambio es debida fundamentalmente al declive en la correlación neta entre la educación del padre y la educación del hijo. Puesto que la mediana de la distribución de los padres es consistentemente más baja que su media en cada cohorte (véase tabla 6), podemos deducir que el volumen de movilidad ascendente superó al de movilidad descendente en todas las cohortes.

En suma, los resultados muestran un declive continuo en el efecto de la educación del padre sobre la educación del hijo, lo que produjo mayor movilidad «pura» (movilidad por encima de la esperada por los cambios habidos en las estructuras educativas de padres e hijos). Acompañando a este proceso, ha habido una tendencia más fuerte, también continua, hacia un aumento en el nivel medio educativo de los españoles. Teniendo en cuenta que ese promedio es casi constante para los padres, es fácil entender porqué los índices de movilidad estructural son tan altos en nuestros datos. Resumiendo, lo que los datos muestran es que el desarrollo educativo del país se ha caracterizado por dos fenómenos: un fuerte incremento general en el nivel educativo de los españoles y una fuerte, aunque menor, democratización del sistema educativo, entendiendo por ésta una mayor igualdad de oportunidades. Esos dos fenómenos no han afectado el nivel de desigualdad educativa, que ha permanecido básicamente constante a lo largo del tiempo.

\subsection{EL PODER PREDICTIVO DEL MODELO A LO LARGO DEL TIEMPO}

Queda por examinar una última cuestión. Se trata de analizar si los logros ocupacionales y educativos de los entrevistados están ahora más o menos determinados por las variables explicativas del modelo que en el pasado. De hecho, no basta con presentar los cambios experimentados por los efectos de las variables explicativas sobre la primera ocupación, tal y como hicimos en las secciones anteriores. Hay también que determinar si esos efectos, tomados en conjunto, han modificado su potencia explicativa respecto a la variación observada en la variable dependiente. 
Hasta el momento hemos omitido deliberadamente la presentación de los $R^{2}$ (y de su descomposición) por cohortes. Adelantamos en la sección 5.1 que el $R^{2}$ no es un buen indicador de la capacidad explicativa de un modelo, o de grupos de variables en ese modelo, si comparamos poblaciones diferentes. Optamos entonces por otro estadístico, el error típico de la regresión, como medida del ajuste. Y ello porque este estadístico no depende, como aquél, de la varianza observada en las variables independientes ${ }^{73}$. Una inspección a la tabla 7 , que presenta ambos estadísticos ${ }^{74}$, será suficiente para ilustrar nuestro argumento.

\section{TABLA 7}

$R^{2}(\%)$ y errores típicos en las regresiones de la ocupación del hijo sobre la educación del bijo y la ocupación y la educación del padre, y de la educación del bijo sobre la ocupación y la educación del padre, por cohortes

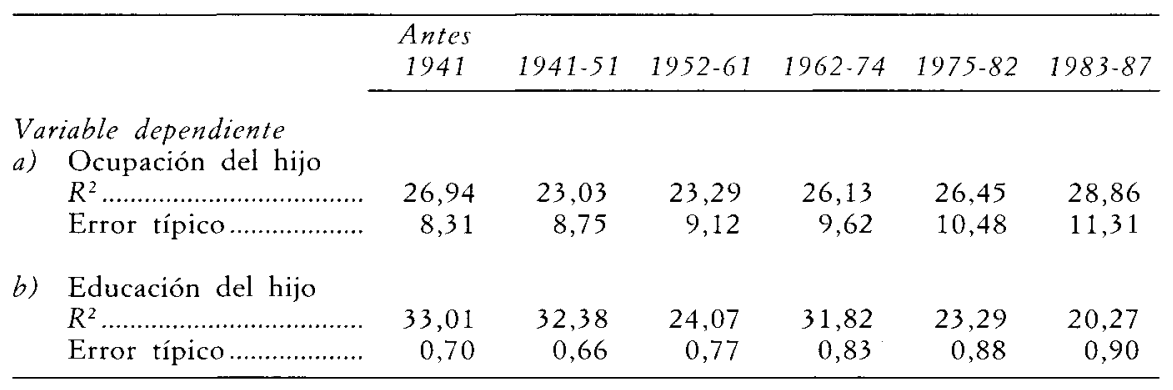

Contrariamente a lo que los $R^{2}$ indican, el modelo ha perdido poder predictivo con el tiempo (véanse los errores típicos), tanto con respecto a la educación como a la primera ocupación de los entrevistados. La creciente varianza de las variables independientes explicaría el fallo del $R^{2}$ en detectar esta tendencia.

El paso de un modelo adscriptivo a un modelo de logro de estatus ha ido acompañado en España de una mayor indeterminación de los logros individuales de los individuos, de manera que otras variables no tomadas aquí en cuenta o, más improbablemente, la pura fortuna tienen hoy más peso en esa determinación que el que tuvieron en el pasado.

73 Véase nota 37.

${ }^{74}$ Para calcular estos estadísticos han sido estimadas regresiones diferentes para cada cohorte. Aunque el efecto directo de la educación del padre sobre la primera ocupación del hijo no alcanzaba la significación en ninguna de las cohortes (excepto para el período anterior a 1941), hemos mantenido esta variable en el modelo por motivos comparativos. Las pautas no cambian al eliminarla del modelo. 


\section{CONCLUSIONES}

Probablemente, una de las tareas más innovadoras y difíciles de este trabajo ha sido la de incorporar los efectos del tiempo a un modelo de «logro de estatus» en España. Redefinimos el «tiempo» en términos de «modernización», basándonos en la historia de nuestro país en los últimos cincuenta años.

La «modernización» ha tenido efectos considerables sobre ese modelo. Por un lado, ha incrementado de forma notable las oportunidades educativas de los entrevistados y, más levemente, sus oportunidades ocupacionales ${ }^{75}$. Por el otro, ha debilitado sustancialmente los procesos de transmisión intergeneracional de estatus, incrementando la movilidad educacional y ocupacional por encima de la que cabría esperar por los cambios experimentados en las correspondientes estructuras de padres e hijos. Ha reforzado notablemente la relación entre los logros educativos de los entrevistados y las posiciones ocupacionales por ellos alcanzadas al ingresar en el mercado de trabajo. $Y$ ha amortiguado el poder informativo que los orígenes sociales y la educación proporcionan para predecir las posiciones que se alcanzarán en la jerarquía ocupacional.

Estas tendencias no se alejan demasiado de las descritas para otros países por otros investigadores, aunque la literatura sobre la movilidad social tiende a explicarlas por los efectos de factores individuales, tales como la industrialización. Por el contrario, en este artículo hemos sostenido y, espero, demostrado que la industrialización es sólo parte, aunque importante, de un proceso mucho más complejo que vagamente hemos definido como «modernización», pero que podría ser definido en términos de «desarrollo», con la expansión del mercado como protagonista.

Me gustaría despojar a estos términos de sus connotaciones morales. La modernización tiene sus propios problemas y efectos negativos. Hemos visto, por ejemplo, cómo ha incrementado la desigualdad ocupacional en España. E1 paso de un modelo de adscripción a un modelo de logro de estatus no implica una amortiguación en la desigualdad. Meramente, cambia las formas en que esa desigualdad se produce y reproduce.

Esta transición ha sido formulada de distintas maneras. Ya sea formulada en términos de «solidaridad orgánica» (Durkheim, 1984), ya sea en términos de «racionalidad» (Weber, 1978) o, más recientemente, en términos de «adquisición» (Parsons, 1951), ha sido en gran parte identificada con el paso de la tradición a la modernidad. Si esto fuera así, las tendencias que hemos identificado en este trabajo no serían una mera consecuencia de la modernización, sino parte de su misma definición. La simultaneidad y regularidad en el tiempo de las tendencias aquí descritas parecen avalar esta interpretación. Diferentes regímenes políticos, ciclos económicos, pautas demográficas y revoluciones culturales han caracterizado el período global analizado. Y, sin

75 Hasta convertir a estas últimas en pérdidas netas, una vez controlados los otros efectos del modelo. 
embargo, los resultados muestran tendencias básicamente constantes y simultáneas en el tiempo, en gran parte insensibles a cualquiera de aquellos factores estructurales tomados individualmente.

Algunos de los resultados presentados refutan parcialmente esta interpretación, indicando que la relación entre adscripción y logro de estatus, por un lado, y tradición y modernidad, por el otro, debe plantearse en términos menos simples y deterministas. Nuestros datos, por ejemplo, parecen apuntar hacia un rebrote en la importancia de los componentes adscriptivos, al menos para los niveles educativos más altos, una vez que el proceso de igualación educativa adquiere manifestaciones masivas. Es pronto para determinar si este fenómeno es una característica exclusiva de España, esto es, una expresión histórica y particular, o si, por el contrario, apunta hacia características universales compartidas por todas las sociedades desarrolladas.

La insensibilidad observada en las tendencias de la movilidad social a los efectos de cambios estructurales particulares podría ser también una simple consecuencia de mi incapacidad para aislarlos. Creo que esto es parcialmente verdad. Más investigaciones son necesarias si queremos describir fehacientemente un modelo social tan complejo como el aquí analizado.

Nuestros esfuerzos deberían dirigirse, por un lado, hacia un mejor uso de nuestras herramientas de trabajo. La escala de prestigio de Treiman, en la que hemos basado gran parte de nuestro trabajo, puede o no reflejar con rigor la realidad española. Su configuración como escala continua dificulta el estudio pormenorizado de categorías ocupacionales de gran interés sustantivo, así como el estudio de los flujos de trabajadores entre esas categorías a lo largo del tiempo. Su demostrada regularidad en el tiempo cuestiona de algún modo nuestros hallazgos sobre la regularidad de las tendencias en la movilidad.

Por otro lado, cualquier investigación que, como ésta, excluya de su estudio a grandes segmentos de la población debe considerarse, cuando menos, incompleta. La exclusión en este estudio de todas las mujeres resulta, creo, justificada ${ }^{76}$. Esta exclusión plantea, sin embargo, varios problemas que van más allá de la omisión de más de la mitad de la población. Las pautas históricas en la movilidad social de los varones no pueden entenderse ni explicarse sin tener en cuenta los efectos que sobre ellas han tenido la progresiva incorporación de la mujer al mercado de trabajo y los procesos de movilidad en que la mujer se ha visto envuelta. Esos efectos apenas han sido analizados en este trabajo. Si bien no alterarían los resultados aquí presentados, sí podrían influir en las interpretaciones of recidas.

Por último, nuestros esfuerzos debieran dirigirse hacia la construcción de modelos donde la descripción de secuencias de eventos tenga prioridad sobre la determinación de leyes causales. Algo de esto se ha intentado en este trabajo. Hemos mostrado, por ejemplo, cómo la pauta decreciente en el efecto de la ocupación del padre sobre las primeras oportunidades ocupacionales de los entrevistados, de alguna manera precedió (fue más rápida que) las mejoras

it Véase sección 4 de este trabajo. 
en sus niveles educativos. En esencia, lo que esto significa es que, en algún punto de nuestra historia contemporánea, principalmente en los años cincuenta y sesenta, una o varias generaciones de españoles rompieron bruscamente con el pasado a través del cambio ocupacional (por ejemplo, migrando del campo a la ciudad o del campo y la ciudad al extranjero, etc.). Sólo con su trabajo y esfuerzo, sus hijos pudieron alcanzar mejores historiales educativos y, valiéndose de ellos, mejores posiciones de partida en la jerarquía ocupacional.

\section{REFERENCIAS}

ACHEN, Christopher H. (1982): Interpreting and Using Regression, Sage University Papers Series on Quantitative Application in the Social Sciences, 07-021, Beverly Hills and London: Sage Pubns.

Agresti, Allan (1990): Categorical Data Analysis, New York, Chichester, Brisbane, Toronto, Singapore: John Wiley \& Sons, Inc.

Blalock, H. M., Jr. (1971): «Causal Inferences, Closed Populations, and Measures of Association», en H. M. Blalock, Jr. (ed.), Causal Models in the Social Sciences, Chicago: Aldine-Atherton, pp. 139-152.

Blau, Peter M., y Duncan, Otis Dudley (1967): The American Occupational Structure, New York: Free Press.

Breiser, Ronald L. (1981). «The Social Class Structure of Occupational Mobility», American Journal of Sociology, 90: 1002-1021.

- (1990): «Intermediate Classes and Social Structure», en R. Breiger (ed.), Social Mobility and Social Structure, Cambridge: Cambridge University Press, pp. 225-245.

CACHÓN ROdRíguez, Lorenzo (1989): ¿Movilidad social o trayectorias de clase?, Madrid: Centro de Investigaciones Sociológicas.

- CaRABAÑa, Julio (1983): Educación, ocupación e ingresos en la España del siglo XX, Madrid: Ministerio de Educación y Ciencia.

- (1989): La adaptación de la Escala Internacional de Prestigio de Treiman, Madrid (sin publicar).

CARR, Raymond (1989): Spain 1808-1975, 2nd ed., Oxford: Oxford University Press.

ClogG, Clifford C. (1981): «Latent Structure Models of Mobility», American Journal of Sociology, 86: 836-868.

Cuadrado Roura, Juan R. (1990): «Cambio estructural, terciarización y remodelación territorial», en José Luis García Delgado (ed.), Economía española de la transición y la democracia, Madrid: Centro de Investigaciones Sociológicas, pp. 169-191.

DízZ NiCOLÁs, Juan (1990): «La población española», en Salvador Giner (ed.), España. Sociedad y Politica, Madrid: Espasa-Calpe, pp. 75-106.

Díez Nicolás, Juan; Martínez Lazaro, Ubaldo, y Porro Minondo, María José (1975): «Education and Social Mobility in Spain», en Education, Inequality and Life Chances, vol. 1, París: Organization for Economic Cooperation and Development, pp. 563. 612.

Draper, N. R., y Smith, H. (1966): Applied Regression Analysis, New York, London, Sidney: John Wiley \& Sons, Inc.

DunCan, Otis D. (1961): «A Socioeconomic Index for all Occupations», en Albert J. Reiss et al., Occupations and Social Status, New York: Free Press of Glencoe, pp. 109138 .

- (1971): «Path Analysis: Sociological Examples», en H. M. Blalock, Jr. (ed.), Causal Models in the Social Sciences, Chicago: Aldine-Atherton, pp. 115-137. 
DurkHeim, Emile (1984): The Division of Labor in Society, New York: The Free Press.

ERIKSON, Robert, y GoldTHORPE, John (1987a): «Commonality and Variation in Social Fluidity in Industrial Nations. Part I: A Model for Evaluating the FJH Hypothesis», European Sociological Review, 3 (May): 1-22.

- (1987b): «Commonality and Variation in Social Fluidity in Industrial Nations. Part II: The Model of Core Fluidity Applied», European Sociological Review, 3 (September): $145-166$.

Featherman, David L., y Hauser, Robert M. (1978): Opportunity and Change, New York: Academic Press.

Garcia Delgado, José Luis (1990): «Claves de unos años decisivos», en José Luis García Delgado (ed.), Economía española de la transición y la democracia, Madrid: Centro de Investigaciones Sociológicas, pp. XV-XXVIII.

Garcia DelGado, José Luis, y ABAD BALBOA, Carlos (1990): «La agricultura y la alimentación: una nueva etapa de cambio estructural», en José Luis García Delgado (ed.), Economia española de la transición y la democracia, Madrid: Centro de Investigaciones Sociológicas, pp. $119-165$.

Grusky, David B., y Hauser, Robert M. (1984): «Comparative Social Mobility Revisited: Models of Convergence and Divergence in 16 Countries», American Sociological Review, 49: 19-38.

Gujaraty, Damodar N. (1988): Basic Econometrics, Singapore: McGraw-Hill International Editions.

Hanushek, Eric A., y Jackson, John E. (1977): Statistical Methods for Social Scientists, San Diego, California: Academic Press.

Harrison, Joseph (1985): The Spanish Economy in the Twentieth Century, New York: St. Martin's Press.

HECKMAN, James J. (1976): «The common structure of statistical models of truncation, sample selection and limited dependent variables and a simple estimator for such models», Annuals of Economic and Social Measurement, 5/4: 421-445.

HERNANDEZ, Francesc (1990): «Estructura ocupacional y mercado de trabajo en España», en Salvador Giner (ed.), España. Sociedad y Politica, Madrid: Espasa-Calpe, pp. 143 167.

Hout, Michael (1983): Mobility Tables, Sage University Papers Series on Quantitative Application in the Social Sciences, 07-031, Beverly Hills and London: Sage Pubns.

- (1989): Following in Father's Footsteps: Social Mobility in Ireland, Cambridge: Harvard University Press.

JENCKS, Christopher (1990): «What is the True Rate of Social Mobility?», en R. Breiger, Social Mobility and Social Structure, Cambridge: Cambridge University Press.

Jencks, Christopher; Smith, Marshall; Acland, Henry; Bane, May Joe; Cohen, David; Gints, Herbert; Heyns, Barbara, y Michelson, Stephan (1972): Inequality: A Reassessment of the Effect of Family and Schooling in America, New York: Basic Books.

Kelley, Jonathan, y KLEIN, Herbert S. (1981): Revolution and the Rebirth of Inequality. A Theory Applied to the National Revolution in Bolivia, Berkeley: University of California Press.

Lieberman, Sima (1982): The Contemporary Spanisb Economy: A Historical Perspective, London, Boston: Allen \& Unwin.

Lipset, S. M., y ZetterberG, H. L. (1959): «Social Mobility in Industrial Societies», en M. L. Lipset y R. Bendix, Social Mobility in Industrial Society, Berkeley: University of California Press.

Mare, Robert D., y WinsiilP, Christopher (1991): Models for Sample Selection Bias (sin publicar).

MCClendon, Mckee J. (1977): «Structural and Exchange Components of Vertical Mobility», American Sociological Review, 42: 56-74.

Miguel, Amando de (1967): El prestigio de las ocupaciones entre los jóvenes españoles, Madrid: Anales de Sociología, 2.

Ministerio de Trabajo y Seguridad Social (1986): Mercado de trabajo en España durante 1985. Coyuntura y programas de actuación, Madrid. 
Moreno, Luis (1990): «Las fuerzas políticas españolas», en Salvador Giner (ed.), España. Sociedad y Politica, Madrid: Espasa-Calpe, pp. 285-313.

MYRO SÁNCHEZ, Rafael (1990): «La evolución de las principales magnitudes: una presentación de conjunto», en José Luis García Delgado (ed.), Economia española de la transición y la democracia, Madrid: Centro de Investigaciones Sociológicas, pp. 527-557.

Parsons, Talcott (1951): The Social System, Glencoe, Illinois: The Free Press.

Penteño Muño, Andrés (1990): «Desempleo, fuerza de trabajo y mercado laboral», en José Luis García Delgado (ed.), Economía española de la transición y la democracia, Madrid: Centro de Investigaciones Sociológicas, pp. 395-419.

Pérez Yruela, Manuel (1990): «La sociedad rutal», en Salvador Giner (ed.), España. Sociedad y Politica, Madrid: Espasa-Calpe, pp. 199-241.

SLgura, Julio (1990): «Del primer Gobierno socialista a la integración en la CEE: 19831985», en José Luis García Delgado (ed.), Economía española de la transición y la democracia, Madrid: Centro de Investigaciones Sociológicas, pp. 119-165.

Simkus, Albert (1984): «Structural Transformations and Social Mobility in Hungary: 1938-1973», American Sociological Review, 49: 291-307.

Sobel, Michael (1983): «Structural Mobility, Circulation Mobility and the Analysis of Circulation Mobility: a Conceptual Mismatch», American Sociological Review, 48: $721-727$.

Sobel, Michael; Hout, Michael, y Duncan, Otis Dudley (1985): «Exchange, Structure, and Symmetry in Occupational Mobility», American Journal of Sociology, 87:578611.

SPSS Inc. (1990): Base Manual and Reference Guide, Chicago.

Stinchicombe, Arthur L. (1979): «Social Mobility in Industrial Labor Markets», Acta Sociologica, 22: 217-245.

Tamames, Ramón (1988): Historia de España, dirigida por Miguel Artola; 7 : «La República. La Era de Franco», Madrid: Alianza Editorial.

Tlzanos, José Félix (1990): «Clases sociales», en Salvador Giner (ed.), España. Sociedad y Politica, Madrid: Espasa-Calpe, pp. 109-140.

Treiman, Donald J. (1975): «Problems of Concepts and Measurement in the Comparative Study of Occupational Mobilitys, Social Science Research, 4: 182-230.

- (1977): Occupational Prestige in Comparative Perspective, New York: Academic Press.

Tumin, Melvin M., y Feldman, Arnold S. (1961): Social Class and Social Change in Puerto Rico, Princeton: Princeton University Press.

VÁzQuez, Juan A. (1990): «Crisis, cambio y recuperación industrial», en José Luis García Delgado (ed.), Economía española de la transición y la democracia, Madrid: Centro de Investigaciones Sociológicas, pp. 81-117.

Weber, Max (1978): Economy and Society, Berkeley: University of California Press. 


\section{RESUMEN}

Esta investigación analiza empíricamente las tendencias históricas en la influencia de los orígenes sociales de los españoles varones (tal y como se reflejan en los historiales educativos y ocupacionales de sus padres), sobre sus propios logros educativos, y sus oportunidades ocupacionales al ingresar en el mercado de trabajo. Para llevarla a cabo se ha elaborado un modelo corregido de «logro de estatus», a partir del modelo formulado en 1967 por Blau y Duncan en The American Occupational Structure. Se intenta establecer las causas estructurales que acompañaron a los cambios en esas tendencias, así como su influencia sobre los procesos de transmisión intergeneracional de estatus de padres a hijos (procesos de movilidad social). Los resultados muestran que el tiempo histórico, interpretado como un indice de «modernización», ha tenido tres importantes efectos sobre aquel modelo: ha incrementado notablemente las oportunidades educacionales de los españoles y, más levemente, sus oportunidades ocupacionales iniciales; ha debilitado sustancialmente los procesos de transmisión intergeneracional de estatus, incrementando la movilidad educativa y ocupacional; y, finalmente, ha reforzado la relación entre los logros educacionales y las recompensas ocupacionales de los españoles. Para analizar el modelo se han utilizado principalmente técnicas de regresión múltiple (con dummy variables) y el método propuesto por McClendon en 1977 para analizar y descomponer la movilidad intergeneracional en sus componentes de movilidad estructural y de intercambio.

\section{ABSTRACT}

In this empirical research the author describes patterns of social change in Spain in the last 50 years, and connects them to changes in the relationship between Spaniards' social origins (as defined by their fathers' educational and occupational backgrounds) and educational and occupational achievements when entering into the labor market. The author tests a modified version of the model of status attainment developed in 1967 by Blau and Duncan in The American Occupational Structure. It is the author's purpose to determine the structural causes behind changes in those tendencies, and to determine their influence on processes of inter-generational transmission of status between fathers and sons (mobility processes). The results show that «time», interpreted as an index of modernization, has had three important effects on such a model: It has strongly increased Spaniards' educational opportunities and, more slightly, their initial occupational chances. It has substantially weakened the processes of inter-generational transmission of status, increasing educational and occupational mobility. And finally, modernization has strengthened the relationship between Spaniards' educational achievements and occupational rewards. The data, based on a macro survey conducted in Spain in 1988 , were analized using multiple regression techniques (with dummy variables), and the method proposed by McClendon in 1977 for decomposing inter-generational mobility in its structural and exchange components. 